\title{
Multiciliated Cells in Animals
}

\author{
Alice Meunier ${ }^{1}$ and Juliette Azimzadeh ${ }^{2}$ \\ ${ }^{1}$ Institut de Biologie de l'Ecole Normale Supérieure, Institut National de la Santé et de la Recherche Médicale \\ U1024, Centre National de la Recherche Scientifique UMR8197, 75005 Paris, France \\ ${ }^{2}$ Institut Jacques Monod, Centre National de la Recherche Scientifique UMR7592, Université Paris-Diderot, \\ 75013 Paris, France \\ Correspondence: ameunier@biologie.ens.fr; juliette.azimzadeh@ijm.fr
}

\begin{abstract}
Many animal cells assemble single cilia involved in motile and/or sensory functions. In contrast, multiciliated cells (MCCs) assemble up to 300 motile cilia that beat in a coordinate fashion to generate a directional fluid flow. In the human airways, the brain, and the oviduct, MCCs allow mucus clearance, cerebrospinal fluid circulation, and egg transportation, respectively. Impairment of MCC function leads to chronic respiratory infections and increased risks of hydrocephalus and female infertility. MCC differentiation during development or repair involves the activation of a regulatory cascade triggered by the inhibition of Notch activity in MCC progenitors. The downstream events include the simultaneous assembly of a large number of basal bodies (BBs) _ from which cilia are nucleated_-in the cytoplasm of the differentiating MCCs, their migration and docking at the plasma membrane associated to an important remodeling of the actin cytoskeleton, and the assembly and polarization of motile cilia. The direction of ciliary beating is coordinated both within cells and at the tissue level by a combination of planar polarity cues affecting BB position and hydrodynamic forces that are both generated and sensed by the cilia. Herein, we review the mechanisms controlling the specification and differentiation of MCCs and BB assembly and organization at the apical surface, as well as ciliary assembly and coordination in MCCs.
\end{abstract}

M ulticiliated cells (MCCs) form hundreds of motile cilia that beat in a coordinated fashion to generate a fluid flow or displace particles and cells. In the respiratory tract, motile cilia are required for the clearance of mucus that traps inhaled particles and pathogens. MCCs also drive the flow of cerebrospinal fluid in the brain ventricles and allow egg transportation along the oviduct. As a consequence, genetic diseases that disrupt cilia-generated fluid flow, such as primary ciliary dyskinesia, result in chronic recurrent respiratory infections, increased risks of hydrocephalus, and female in- fertility (Lee 2011, 2013; Boon et al. 2014; Popatia et al. 2014; Wallmeier et al. 2014). Outside vertebrates, MCCs are involved in generating fluid flows or driving the locomotion of a variety of animal species (Gibbons 1961; Tyler 1981; Tamm and Tamm 1988). Cilia in MCCs are assembled from basal bodies (BBs), which are ninefold symmetrical microtubule (MT)-based structures related to the centrioles found within the centrosome. In most mammalian cell types, the older centriole, called the mother centriole, can convert to a $\mathrm{BB}$ and template the assembly of a primary cilium, which is typically a nonmotile

Editors: Wallace Marshall and Renata Basto

Additional Perspectives on Cilia available at www.cshperspectives.org

Copyright (C) 2016 Cold Spring Harbor Laboratory Press; all rights reserved; doi: 10.1101/cshperspect.a028233

Cite this article as Cold Spring Harb Perspect Biol 2016;8:a028233 
cilium involved in sensory functions (Goetz and Anderson 2010). In contrast, MCCs simultaneously assemble up to several hundred motile cilia while undergoing terminal differentiation. These cilia are formed following assembly a large number of BBs in the cytoplasm and their migration to the apical membrane (Sorokin 1968; Steinman 1968; Anderson and Brenner 1971; Dirksen 1971; Sandoz and Boisvieux-Ulrich 1976; Tyler 1981).

MCC cilia usually show a planar beating pattern, with a fast power stroke and a slower recovery stroke occurring in the same plane. To generate a directional fluid flow, cilia must beat in the right orientation with respect to the polarity of the whole tissue. The direction of ciliary beat depends on the position of BBs within the plane of the apical membrane, or BB rotational polarity. This polarity is evidenced by the presence of $\mathrm{BB}$ appendages that align with the axis of ciliary beating: the basal foot and the striated ciliary rootlet (Gibbons 1961; Sorokin 1968; Dirksen 1971; Anderson 1972; Reed et al. 1984). These appendages anchor cytoskeletal networks linking the BBs to each other and to the apical cell junctions. Polarity proteins localize to the centrioles and to the cell junctions to connect $\mathrm{BB}$ polarity to the planar polarity of the epithelium.

We will first give an overview of the phylogenetic distribution of MCCs in animals, and then we will review the current knowledge on MCC specification and differentiation, BB assembly, docking, and positioning at the apical membrane, ciliogenesis, cellular and tissue-level polarization of MCCs, and the regulation of MCC function.

\section{MULTICILIATED EPITHELIA ACROSS ANIMALS}

In mammals, MCCs are present in the respiratory tract, the brain ventricles, the oviduct, and the efferent ducts (Brightman and Palay 1963; Sorokin 1968; Anderson and Brenner 1971; Dirksen 1971; Danielian et al. 2016). MCCs are also found transiently in kidney tubules and in the esophagus during fetal development (Katz and Morgan 1984; Menard 1995). In Xen- opus tadpoles, MCCs are found in the skin, the trachea, and the digestive tract (Steinman 1968; Werner and Mitchell 2012; Walentek et al. 2015). In addition, MCCs are present in the pronephros in zebrafish and Xenopus to facilitate urine flow (Vize et al. 2003; Kramer-Zucker et al. 2005; Liu et al. 2007). Cell types with multiple nonmotile cilia also exist, such as olfactory neurons in vertebrates (Cuschieri and Bannister 1975; Zielinski and Hara 1988; Ying et al. 2014). Outside of vertebrates, MCCs with similar ultrastructural features, in particular BBs decorated by a basal foot, are found within a group of protostome animals called Lophotrochozoa. Within this group, MCCs are particularly well described in mollusks and flatworms (Gibbons 1961; Rieger 1981; Reed et al. 1984; Basquin et al. 2015). In flatworms, epidermal MCCs are required for locomotion, either by ciliary gliding along solid substrates or swimming through water (Rompolas et al. 2013; Basquin et al. 2015). MCCs are also present in protonephridia, the branched tubules that form the excretory system of flatworms and other Lophotrochozoa (Rink et al. 2011; Thi-Kim Vu et al. 2015). MCCs are absent in arthropods and nematodes (Giribet and Ribera 1998). Outside bilaterians, MCCs are found in ctenophores (Tamm and Tamm 1988) and in sponges; although, in the latter case, each $\mathrm{BB}$ is associated to an accessory $\mathrm{BB}$ (i.e., like in a centrosome), suggesting that distinct mechanisms are used for BB assembly in these cells (Boury-Esnault et al. 1999). It is worth mentioning that MCCs are also found outside of animals in phyla as diverse as plants, ciliates, or amoebozoa (Tamm et al. 1975; Mikrjukov and Mylnikov 1998; Hodges et al. 2010). This distribution is most likely the result of convergent evolution, however, because these phyla originate from distinct mono- or biflagellated unicellular ancestors (Adl et al. 2012; Azimzadeh 2014).

\section{SPECIFICATION AND DIFFERENTIATION}

\section{Notch Inhibition}

The very first steps of the MCC differentiation process are particularly well described in the 
mammalian respiratory system. The adult airways are lined by a pseudostratified epithelium containing MCCs, mucus-secreting cells, and basal cells. During development, they all derive from $\mathrm{p} 63^{+}$progenitors (Rock and Hogan 2011). Notch sets the balance between ciliated versus secretory lineage. In the absence of Notch signaling, the MCC population expands at the expense of the secretory lineage (Guseh et al. 2009; Tsao et al. 2009; Morimoto et al. 2010). The inverse happens after transgenic Notch activation in the embryonic airways (Guseh et al. 2009). The same dynamics exists between MCCs and transporting cells in the zebrafish pronephros (Liu et al. 2007). Notch inhibition also drives MCC specification in mouse oviducts and brain ventricles (Kessler et al. 2015; Kyrousi et al. 2015). Recently, bone morphogenetic protein (BMP) signaling has been shown to interact with the Notch pathway to control mucociliary differentiation of vertebrate epithelia (Cibois et al. 2015).

In the adult, ciliated cells can differentiate from both basal progenitors and secretory cells in mouse airways (Rawlins et al. 2009; Lafkas et al. 2015; Pardo-Saganta et al. 2015b; Watson et al. 2015). Electron microscopy (EM) suggests the same events of (trans-)differentiation from secretory-to-ciliated cells in human and quail oviducts under hormonal control (Sandoz and Boisvieux-Ulrich 1976; Sandoz et al. 1976; Hagiwara 1995). Secretory cells are thus proposed to act as transit-amplifying cells by self-renewing and giving rise to terminally differentiated postmitotic MCCs. Depending on the context, the mechanism by which Notch proceeds to segregate secretory and ciliated lineages seems to differ. Classical Notch-mediated lateral inhibition has been proposed, during development (Tsao et al. 2009; Morimoto et al. 2010; Gomi et al. 2015; Mori et al. 2015) or repair (PardoSaganta et al. 2015a), to lead to the mosaic distribution of MCC among secretory cells in mouse airways (Fig. 1). In the zebrafish pronephros and the Xenopus skin, Notch-lateral inhibition is also reported to drive the mosaic differentiation pattern of MCC versus transporting or secretory epithelial cells (Deblandre et al. 1999; Liu et al. 2007; Ma and Jiang 2007). In addition, microRNAs, such as miR449, are specifically expressed in MCC progenitors in Xenopus skin and human airway developing epithelium, where they repress the Notch pathway by targeting Notch 1 and its ligand DLL1 (Marcet et al. 2011). Finally, in the adult mouse homeostatic airways, a recent study proposes that basal cells continuously supply their daughter secretory cells with a Notch ligand to avoid their terminal (trans-)differentiation into MCC (Lafkas et al. 2015; Pardo-Saganta et al. 2015b).

\section{Master Regulators of the MCC Differentiation Program}

Two master regulators of MCC fate differentiation downstream from Notch inhibition have been discovered recently: GEMC1 (geminin coiled-coil containing protein 1) and IDAS

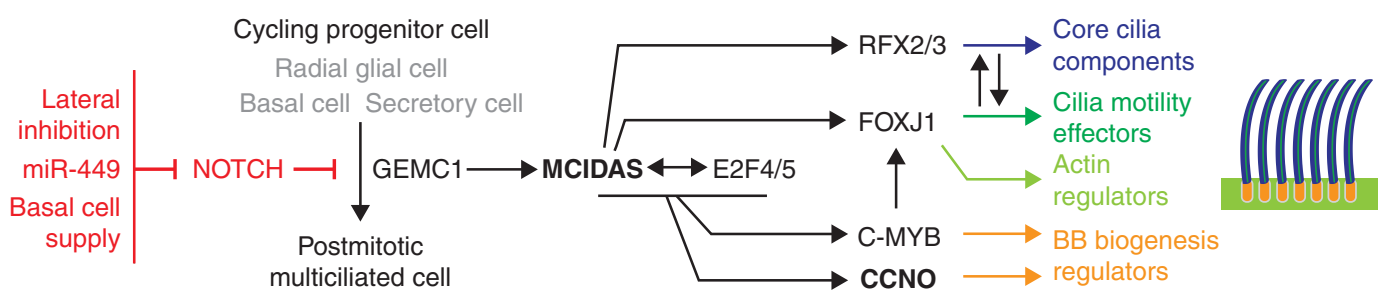

Figure 1. Regulation of multiciliated cell (MCC) differentiation in vertebrates. MCC differentiation is triggered by Notch inhibition in radial glial cells of the ependyma, and in basal cells or secretory cells (trans-differentiation) in mucociliary epithelia. Notch inhibition triggers the activation of a regulatory cascade that involves the geminin-related proteins GEMC1 and MCIDAS, the transcription factors E2F4/5, RFX2/3, FOXJ1, and C$\mathrm{MYB}$, and the cyclin-like protein CCNO. This cascade triggers cell-cycle exit, basal body (BB) amplification, cytoskeleton remodeling, and ciliogenesis (see text for details). 
(a cousin of the Gemini in ancient Greek mythology). As their name suggests, both have coiled-coil domains related to geminin, a protein involved in cell-cycle progression and in the balance between proliferation and differentiation (Kroll 2007). GEMC1 was primarily found to promote initiation of DNA replication in vertebrate cells (Balestrini et al. 2010) and was recently found to be necessary for MCC postmitotic commitment in zebrafish pronephros, Xenopus skin, and mouse brain MCCs (Kyrousi et al. 2015; Zhou et al. 2015). IDAS was first found to bind to geminin and to regulate its function in DNA replication licensing in S phase (Pefani et al. 2011). It was later found to be required for MCC differentiation in Xenopus skin/kidney and mammalian airway/brain epithelia, and therefore renamed multicilin or MCIDAS (Stubbs et al. 2012; Kyrousi et al. 2015). Both GEMC1 and MCIDAS are reported to be sufficient to trigger early-onset differentiation of MCC progenitors in the mouse brain (Kyrousi et al. 2015). In addition, they are able to drive ectopic differentiation of MCCs in Xenopus skin/kidney and mouse airway epithelia (Stubbs et al. 2012; Zhou et al. 2015). GEMC1 and MCIDAS are therefore sufficient to trigger the full developmental program for secretoryto-ciliated cell conversion, which is consistent with the finding that this (trans-) differentiation process is Notch-dependent (Lafkas et al. 2015; Pardo-Saganta et al. 2015b). Hierarchically, MCIDAS lies downstream from GEMC1, although the molecular aspect of this control is unknown (Fig. 1). Interestingly, geminin binds to MCIDAS and represses MCC formation in the Xenopus skin (Ma et al. 2014). Because geminin is silenced in cells exiting the cell cycle (Kroll 2007), these three geminin-family proteins may constitute the central network for triggering postmitotic MCC transcriptional program.

\section{Downstream Effectors of the MCC Differentiation Program}

MCIDAS lacks a DNA-binding domain. In Xenopus, it binds to the cell-cycle-repressing transcription factors E2F4/5 (Sadasivam and De-
Caprio 2013; Ma et al. 2014). Expression of a dominant-negative form of E2F4 in the Xenopus skin blocks BB amplification and multiciliation in presumptive MCCs. RNA-seq analysis after coexpression of an inducible form of MCIDAS and of the dominant-negative form of E2F4 suggests that the MCIDAS/E2F4 association is required for the up-regulation of BB components and ciliogenic transcription factors (Fig. 1) (Ma et al. 2014). In addition, mouse mutants for E2F4 and/or 5 fail to form MCCs in the airways and in the efferent ducts (Danielian et al. 2007, 2016). Together with the role of E2F4/5 in cell-cycle exit (Sadasivam and DeCaprio 2013), MCIDAS/E2F4 interaction is proposed to induce the MCC terminal differentiation program. Mcidas mutations are found in patients with congenital mucociliary clearance disorder with reduced generation of multiple motile cilia (RGMC) (Boon et al. 2014). Interestingly, MCIDAS/E2F association is impaired by certain of mutations found in patients ( $\mathrm{Ma}$ et al. 2014).

One transcription factor proposed to mediate $\mathrm{BB}$ amplification MCIDAS/E2F4 complex is C-MYB (Fig. 1) (Stubbs et al. 2012; Ma et al. 2014). C-MYB normally promotes S-phase entry and enhances cycling in a variety of progenitor cells (Ramsay and Gonda 2008). It is, however, up-regulated in zebrafish, Xenopus, and mouse brain/tracheal presumptive MCC progenitors (Tan et al. 2013; Wang et al. 2013; Pardo-Saganta et al. 2015a) where it controls the expression of key BB biogenesis regulators. Depletion of C-MYB leads to a block or a delay in BB amplification in MCCs from zebrafish, Xenopus, and mouse tracheal cells (Tan et al. 2013; Wang et al. 2013). Its effect seems, however, to be redundant with at least one other factor because MCCs can partially recover multiciliogenesis after $c m y b$ deletion in the mouse trachea (Tan et al. 2013). Downstream from the MCIDAS/E2F complex also lies CCNO (Fig. 1) (Stubbs et al. 2012; Ma et al. 2014; Wallmeier et al. 2014), a cyclin-like protein first shown to be involved in oocyte meiosis resumption and apoptosis (Roig et al. 2009; Ma et al. 2013), and then shown to be expressed in MCC progenitors in the Xenopus skin and in the mouse brain, 
airways, and oviducts (Stubbs et al. 2012; Funk et al. 2015; Amirav et al. 2016). Although its partners and molecular function remain to be determined, CCNO mutations or depletion lead to defects comparable to the C-MYB phenotype: defects in BB amplification, docking, and ciliogenesis (Wallmeier et al. 2014; Funk et al. 2015). In humans, mutations in CCNO have been identified as a cause of RGMC and associated with hydrocephalus and female infertility (Wallmeier et al. 2014; Amirav et al. 2016). Interestingly, human mcidas, ccno, and miR449 host gene $c d c 20 b$ are physically colocalized in a genomic region of chromosome 5 and are syntenic with those of Xenopus and mouse (Marcet et al. 2011; Stubbs et al. 2012; Wallmeier et al. 2014).

In parallel to $\mathrm{BB}$ amplification, multiple motile cilia biogenesis is controlled by the deployment of the RFX (regulatory factor X)/ FOXJ1 (forkhead box J1) ciliogenic network (Fig. 1). The current view is that the RFX family of transcription factors is involved in primary and motile cilia formation by directing the expression of core components of all types of cilia (Choksi et al. 2014). The FOXJ1 family has emerged as an additional factor important for the generation of motile cilia by directing the expression of genes required for BB docking, axoneme outgrowth, and motility (Chen et al. 1998; Brody et al. 2000). This view is, however, progressing in MCC epithelia because RFX2 and 3 are also shown to direct the expression of core components of the cilia motility machinery, and to affect cilia beating in Xenopus and mouse (El Zein et al. 2009; Chung et al. 2012, 2014). Interestingly, FoxJ1 and RFX2/3 cross-regulate their expression during vertebrate MCC formation (Yu et al. 2008; El Zein et al. 2009; Didon et al. 2013). In the human airways, RFX3 can enhance FOXJ1-dependent transcription and immunoprecipitation experiments provide evidence for RFX2/3-FOXJ1 interactions, suggesting a role of RFX3 as a cofactor of FOXJ1 for motile ciliogenesis (Didon et al. 2013). Altogether, this raises the possibility that RFX and FOXJ1 form a transcriptional complex in MCC in which RFX factors regulate core cilia genes and cooperate with FOXJ1 to regulate motility genes. Both RFX2 and FOXJ1 expressions are up-regulated following inducible MCIDAS expression in the Xenopus skin, suggesting a control by MCIDAS of the deployment of this ciliogenic program ( $\mathrm{Ma}$ et al. 2014). C-MYB was also reported to drive the expression of FOXJ1 in addition to BB biogenesis regulators, leading to the identification of C-MYB as a core regulator of both early and late steps of multiciliogenesis. In this line, it was shown to trigger the complete multiciliogenesis program in the Xenopus skin, but not in the mouse trachea (Tan et al. 2013).

\section{BB ASSEMBLY}

\section{Dynamics}

Like most other cell types, MCC progenitors contain a centrosome with two centrioles-a mother and a daughter-which serves as the main MT-organizing center. During the course of their differentiation, MCCs must then produce from 30 up to 300 additional centrioles/ BBs. BB amplification has been extensively described by EM in quail, chick, Xenopus, and mammalian MCCs (Sorokin 1968; Steinman 1968; Kalnins and Porter 1969; Dirksen 1971; Sandoz and Boisvieux-Ulrich 1976). Two pathways have been shown to contribute to the final BB population: a "centriolar pathway," where two to six BBs are formed orthogonally to the two preexisting centrosomal centrioles in a manner akin to centriole duplication, and a "deuterosome pathway," where tens of BBs are seen growing on electron-dense spherical structures called deuterosomes. This second pathway evokes the de novo generation of centrioles from blepharoplasts observed in plant male gametes (Mizukami and Gall 1966; Hepler 1976). Some investigators, however, provide evidence supporting the hypothesis that the clusters of centrioles growing on the deuterosomes are primarily nucleated from the centrosomal centrioles (Kalnins and Porter 1969).

Live imaging recently helped to clarify the very first events of $\mathrm{BB}$ amplification and disclosed the origin of deuterosomes in mouse brain MCCs (Fig. 2) (Al Jord et al. 2014). 

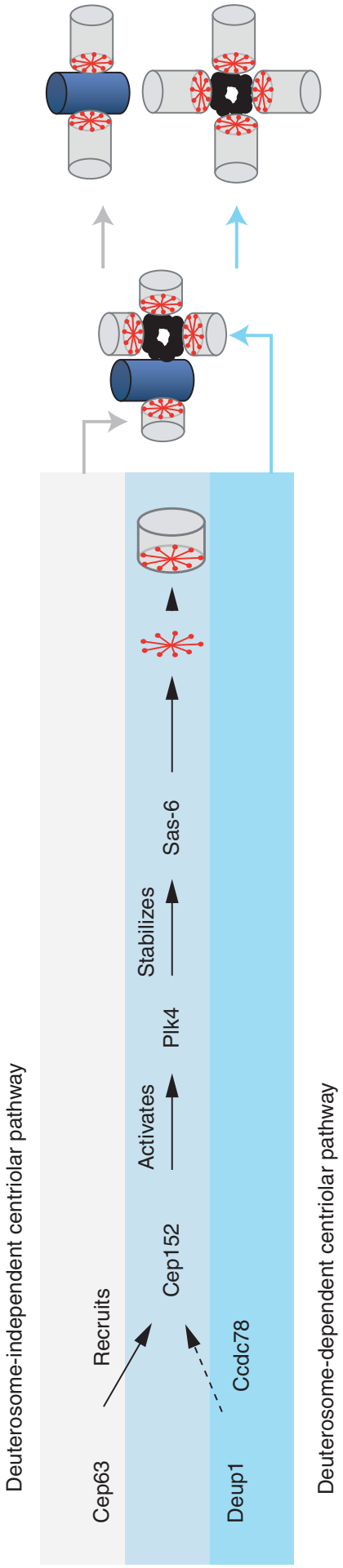

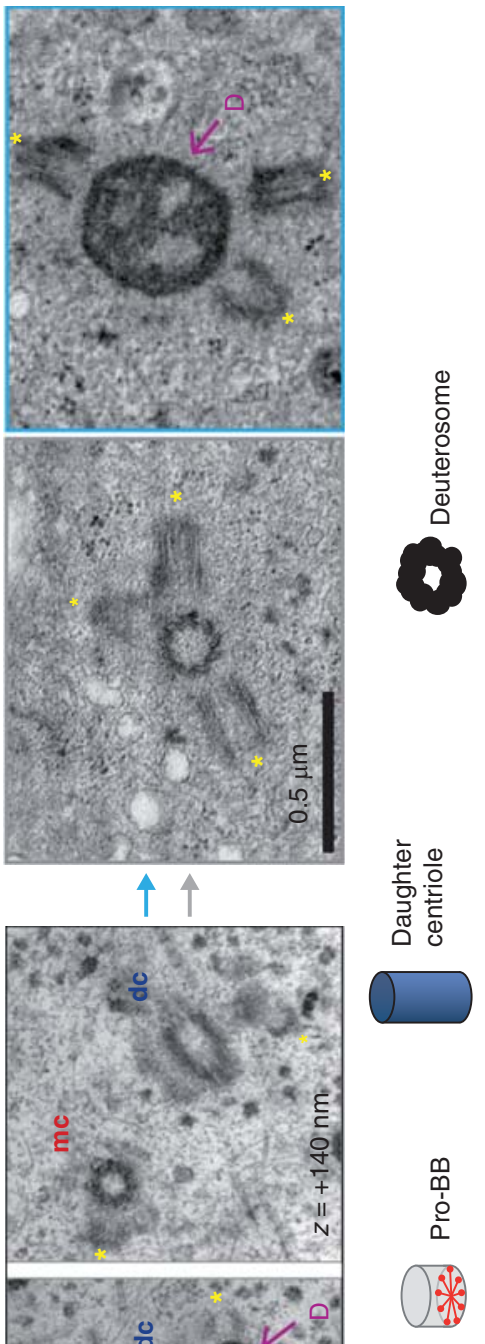

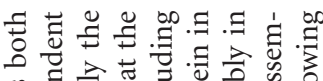

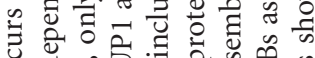
ठु

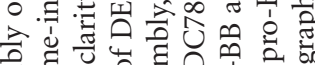

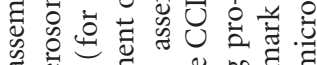

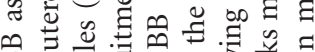

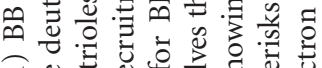

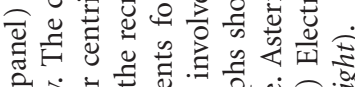

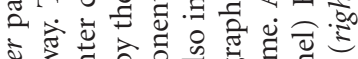

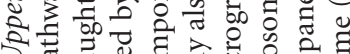

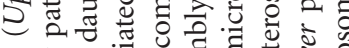

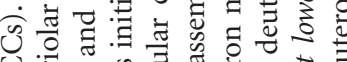
บ. $\leq$ चाँ

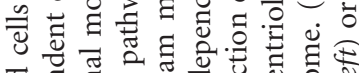
च

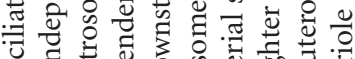

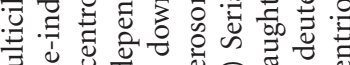

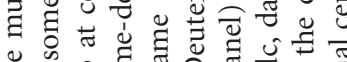
ช

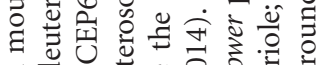
.

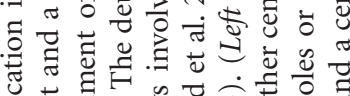

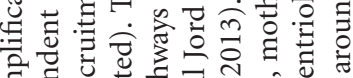

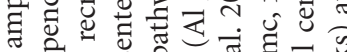

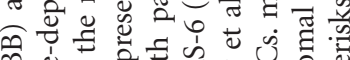

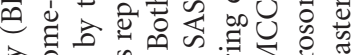

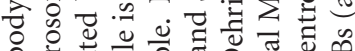

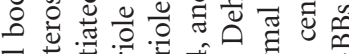
ब

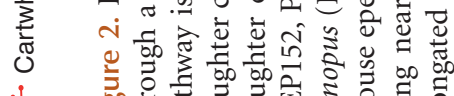

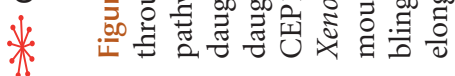


Time-lapse sequences show that deuterosomes together with the pro-BBs they support arise from the proximal part of the daughter centriole. Multiple rounds of deuterosome formation provide the cell with more than a hundred proBBs. Electron and superresolution microscopies indicate that the short pro-BBs remain latent during this phase of amplification (Kalnins and Porter 1969; Al Jord et al. 2014). Once the last deuterosome has been produced, pro-BBs then elongate simultaneously from all the deuterosomes and from the centrosomal centrioles (Zhao et al. 2013; Al Jord et al. 2014). This explains the coexistence of both "deuterosome" and "centriolar" pathways during MCC differentiation, which are seemingly the outcome of the same process originating at the centrosome. Immunostaining experiments suggest that the same dynamics of deuterosome formation and pro-BB amplification occurs in mouse tracheal MCCs (Al Jord et al. 2014).

\section{Molecular Control}

Insights into the molecular control of deuterosome formation and BB amplification in MCCs come from the process of centriole duplication in cycling cells. Centriole duplication is tightly controlled to avoid supernumerary centrosomes responsible for chromosome segregation defects during mitosis (Firat-Karalar and Stearns 2014). Briefly, at the $G_{1} / S$ transition, centrosomal proteins 63 (CEP63) and centrosomal protein 152 (CEP152) form a complex at the proximal end of each centriole, initiating centriole biogenesis (Fig. 2) (Sir et al. 2011; Brown et al. 2013; Lukinavicius et al. 2013). CEP152 is then thought to recruit and/or activate polo-like kinase 4 (PLK4), which stabilizes spindle-assembly 6 homolog (SAS-6) to form the cartwheel structure that templates procentriole assembly in S phase. The level of centriole biogenesis initiators is regulated throughout the cell cycle to avoid the formation of supernumerary centrioles (Firat-Karalar and Stearns 2014).

As mentioned in the previous paragraph, MCC differentiation involves a massive up-reg- ulation of $\mathrm{BB}$ biogenesis regulators. Under the control of MCIDAS/E2F complex and involving C-MYB transcription factor, the expression levels of CEP63, CEP152, and PLK4, among others, is increased at the onset of differentiation (Hoh et al. 2012; Klos Dehring et al. 2013; Wang et al. 2013; Zhao et al. 2013; Ma et al. 2014; Funk et al. 2015). In addition, a paralog of CEP63, CCDC67 (also called deuterosome protein 1, DEUP1) is specifically expressed in vertebrate multiciliated tissues (Zhao et al. 2013; Ma et al. 2014). Although BB amplification through the centriolar pathway seems to be driven by a duplication-like process, downstream from CEP63-CEP152, the deuterosome pathway is driven by DEUP1 (Fig. 2). DEUP1 depletion blocks deuterosome formation and BB amplification in Xenopus skin and mouse tracheal MCCs. Its overexpression in bacteria leads to the formation of spherical structures suggesting self-oligomerization properties. In some transformed cycling cells, DEUP1 can drive the formation of deuterosome-like structures capable of procentriole nucleation (Zhao et al. 2013). It thus seems to be a core structural and functional component of deuterosomes. Consistent with live imaging and EM experiments, DEUP1 accumulates on the proximal part of the daughter centriole during deuterosome formation in mouse brain MCCs (Al Jord et al. 2014). DEUP1 shares $37 \%$ of homology with CEP63 and has retained its ability to associate with centrosomal centrioles and to interact with CEP152. Knockdown experiments in mouse tracheal cells and Xenopus skin suggest that the recruitment of CEP152 by DEUP1 and the subsequent activation of PLK4, enable pro-BB nucleation from deuterosomal structures (Klos Dehring et al. 2013; Zhao et al. 2013). The current view is therefore that in MCCs, CEP152 is recruited by CEP63 or its paralog DEUP1 to drive the centriolar and the deuterosome pathway, respectively, via a unique molecular cascade highjacked from the centriole duplication process (Fig. 2). Although the BB duplication players downstream from SAS-6 are also up-regulated during vertebrate MCC differentiation, their involvement in centriole amplification remains to be determined (Hoh et al. 2012; Klos 
Dehring et al. 2013; Wang et al. 2013; Zhao et al. 2013; Ma et al. 2014; Funk et al. 2015).

The centriole-associated protein CCDC78 has been shown to associate with deuterosomes and to be required for CEP152 recruitment and deuterosome-mediated pro-BB formation in mouse tracheal and Xenopus skin MCCs (Klos Dehring et al. 2013). The CCDC78 and DEUP1 relationship has not been tested yet. CCNO, a cyclin-like protein, is also involved in deuterosome-mediated $\mathrm{BB}$ amplification. Although CCNO partners and function are unknown, patients with mutations in ccno have MCCs with reduced number of cilia (Wallmeier et al. 2014). In particular, ccno mutant mice tracheal cells display larger deuterosomes with fewer pro$\mathrm{BBs}$ suggesting a role for $\mathrm{CCNO}$ in the early onset of amplification (Funk et al. 2015).

\section{Evolutionary Perspective}

DEUP1 appears to be a key component for BB amplification in MCCs. Although CEP63 enables centriole duplication in cycling cells or mild amplification in MCCs, turning on DEUP1 expression allows the switch to massive $\mathrm{BB}$ production. Phylogenetic tree analyses suggest that DEUP1 was duplicated and diverged from CEP63 during vertebrate evolution after ray-finned fish specification (Zhao et al. 2013). Deup1 is thus absent in zebrafish, which specify their MCCs under the same transcriptional cascade as the one of mammalian species and Xenopus (see previous paragraph) (Wang et al. 2013; Zhou et al. 2015). The availability of the single CEP63-mediated centriolar pathway may explain why zebrafish MCCs, observed in the olfactory placode and the pronephric ducts, are reported to have less than 16 cilia (Hansen and Zeiske 1993; Kramer-Zucker et al. 2005). Supporting this hypothesis, mammalian olfactory neurons, which harbor a dozen cilia, are proposed to produce their centrioles through a deuterosome-independent centriolar pathway (Cuschieri and Bannister 1975). Different situations exist in flatworms. Although the marine flatworm Macrostomum lignano has centrosomes and amplifies centrioles through a deuterosome-centriolar pathway (Tyler 1981), the freshwater planarian Schmidtea mediterranea lacks centrosomes and thus amplifies centrioles de novo (Azimzadeh et al. 2012). In both cases, gemc1, mcidas, and deup1 genes are absent, suggesting that centrioles can be massively amplified through centriolar and de novo pathways independently from this specific transcriptional cascade in animal cells. Conserved centriole duplication players are nevertheless required in S. mediterranea MCCs showing that de novo and centriole/deuterosome-derived amplification use unique upstream regulators but common downstream effectors in animals (Azimzadeh et al. 2012).

\section{BB DOCKING AND CILIOGENESIS}

Role of the Actin Cytoskeleton in BB Migration and Docking to the Apical Membrane

Following assembly and simultaneous release from either deuterosomes or centrosomal centrioles, BBs migrate and dock en masse at the apical membrane of MCCs (Ioannou et al. 2013; Al Jord et al. 2014). Pioneering work on differentiating MCCs from quail oviduct revealed that $\mathrm{BB}$ migration and docking depend on actin-myosin (Klotz et al. 1986; Lemullois et al. 1988; Boisvieux-Ulrich et al. 1990). A dense actin meshwork is present at the apical cortex in MCCs and myosin is also enriched in this area (Reverdin et al. 1975; Reed et al. 1984; Klotz et al. 1986; Lemullois et al. 1988; Sandoz et al. 1988; Park et al. 2006, 2008; Pan et al. 2007; Werner et al. 2011). The formation of the apical actin network is temporally linked to $\mathrm{BB}$ docking and involves conserved actin regulators, such as the RhoA and RaclGTPases, the membrane-cytoskeletal linker ezrin, the cross-linking protein filamin $\mathrm{A}$, the nucleator dishevelled-associated activator of morphogenesis 1 (DAAM1), or the F-actin capping protein CapZ-interacting protein (CapZIP) (Gomperts et al. 2004; Pan et al. 2007; Park et al. 2008; Chevalier et al. 2015; Epting et al. 2015; Miyatake et al. 2015; Yasunaga et al. 2015). The expression of several of these actin regulators is triggered by the regulatory network that controls MCC differentiation (Fig. 1) (Gomperts 
et al. 2004; Pan et al. 2007; Chevalier et al. 2015; Miyatake et al. 2015). Apical actin assembly and BB docking in MCCs are orchestrated by the planar cell polarity (PCP) pathway. Originally identified in the Drosophila wing, the PCP pathway is a conserved signaling pathway that governs a range of developmental processes (reviewed in Bayly and Axelrod 2011; Goodrich and Strutt 2011; Devenport 2014). Core PCP components include the intracellular proteins dishevelled ( $\mathrm{Dvl}$ ), diversin (diego in Drosophila), prickle $(\mathrm{Pk})$, the transmembrane proteins frizzled (Fz), Van Gogh-like (Vangl) (strabismus or Van Gogh in Drosophila), cadherin, EGF-like, laminin G-like, seven-pass, and Gtype receptor (Celsr) (flamingo in Drosophila). The control of BB docking by the PCP pathway is an evolutionarily conserved feature because depletion of PCP components inhibit this process both in vertebrates and planarian MCCs (Park et al. 2006, 2008; Tissir et al. 2010; Almuedo-Castillo et al. 2011). Depleting the core PCP component Dvl or the PCP effectors inturned and fuzzy in Xenopus MCCs decreases the density of the apical actin meshwork and strongly affects ciliogenesis (Park et al. 2006, 2008). RhoA, which is present throughout the apical cortex and is essential to BB docking, is activated (i.e., converted to its GTP-bound form) specifically at BBs in a Dvl-dependent manner (Pan et al. 2007; Park et al. 2008). Recruitment of both Dvl and RhoA at BBs is dependent on inturned, which is itself recruited by nephrocystin 4 (NPHP4), a component of the

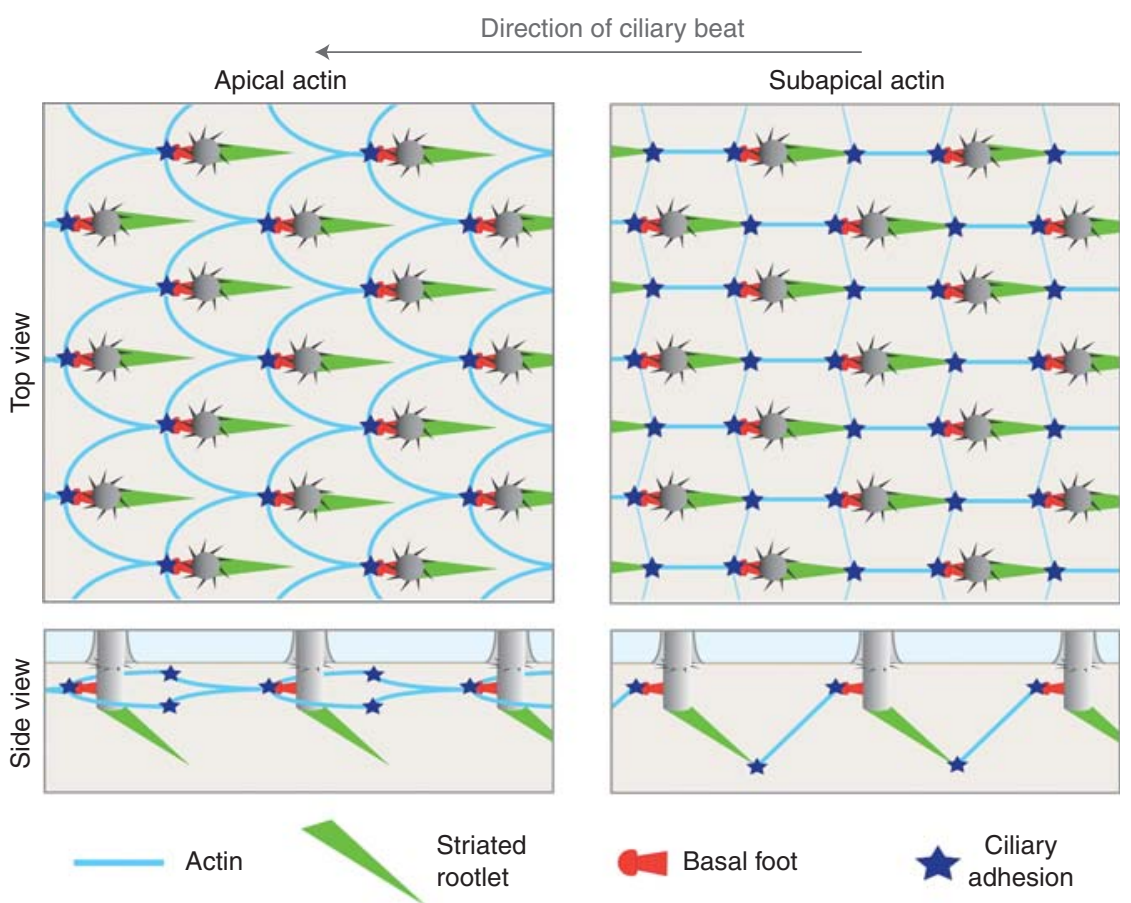

Figure 3. A model illustrating the architecture of the actin cytoskeleton in Xenopus skin multiciliated cells (MCCs). The drawings represent the basal bodies (BBs) and either the actin apical or subapical pools in mature MCCs. This organization of the subapical network is proposed in Antoniades et al. (2014) and the model of apical actin organization is based on immunofluorescence data from the same study. Both actin pools are connected to the BBs by ciliary adhesions located in the vicinity of the basal feet (note that the exact localization - near or at the basal feet—remains to be determined) (Antoniades et al. 2014). In addition, actin bridges forming the subapical pool are connected to rootlet tips both along the direction of ciliary beat and perpendicular to this direction (Werner et al. 2011; Antoniades et al. 2014). For clarity, only the actin bridges connecting the $\mathrm{BBs}$ along the direction of ciliary beat are represented in the side view of the subapical actin network. 
ciliary transition zone that also binds to the striated rootlet in MCCs (Park et al. 2008; Yasunaga et al. 2015). In addition, inturned recruits the PCP effector DAAM1, and Dvl facilitates the activation of CapZIP by the kinase extracellular signal-regulated kinase 7 (ERK7) (Miyatake et al. 2015; Yasunaga et al. 2015). Another potential PCP effector affecting the actin cytoskeleton is the recently characterized flattop (FLTP) protein, which is required for $\mathrm{BB}$ docking in mouse MCCs (Gegg et al. 2014). Taken together, these results support that BB docking and the organization of apical actin are, in large part, orchestrated at the BBs by the local, PCP-dependent recruitment of actin regulators.

Studies in Xenopus reveal that the apical actin cap in mature MCCs is composed of two distinct but interconnected actin pools (Fig. $3)$. The apical pool is a very stable meshworklike network that surrounds the BBs (Werner et al. 2011; Ioannou et al. 2013; Antoniades et al. 2014). The apical actin pool starts accumulating in the form of actin foci during early steps of MCC intercalation and becomes organized after BBs have docked (Ioannou et al. 2013). The subapical pool forms just below the apical pool $(\sim 0.5 \mu \mathrm{m}$ below the apical surface) and consists of short actin bridges that connect neighboring BBs (Werner et al. 2011; Antoniades et al. 2014). During intercalation, migrating $\mathrm{BBs}$ are clustered together and connected to the cell periphery by actin cables. Disruption of this internal actin network by partially depleting the nucleotide-binding protein 1 (Nubp1) ATPase correlates with defective BB migration. Following BB docking, the internal actin network is replaced, or possibly remodeled, into the subapical network (Ioannou et al. 2013). Remarkably, both the internal actin network and subapical actin bridges are connected to the BBs via a protein complex known to regulate focal adhesions, which link the actin cytoskeleton to the extracellular matrix. The focal adhesion components vinculin, paxilin, talin, and focal adhesion kinase (FAK) localize at the BBs, forming anchor sites called "ciliary adhesions" by analogy to focal adhesions. In agreement with this idea, BBs in intercalating MCCs from FAK morphants are more dispersed that in control cells and many BBs fail to associate to actin cables, which correlates with a defect in BB migration and docking (Antoniades et al. 2014).

\section{BB Docking and Ciliary Assembly}

As initially hypothesized by Sergei Sorokin, mother centriole docking at the onset of primary ciliogenesis requires the binding of a ciliary vesicle at the distal centriole and subsequent fusion of the ciliary vesicle with the plasma membrane (Sorokin 1962; and reviews by Rohatgi and Snell 2010; Ishikawa and Marshall 2011; Reiter et al. 2012; Wei et al. 2015). The ciliary vesicle is formed after recruitment of smaller vesicles to mother centriole distal appendages and fusion of these vesicles under the control of membrane-remodeling proteins and the Rab11/Rab8 cascade of GTPases (Lu et al. 2015). Rab8 and its activator Rabin8 interact with the distal appendage component CEP164 (Schmidt et al. 2012). BBs with docked vesicles have also been observed in vertebrate MCCs (Sorokin 1968; Dirksen 1971; Lemullois et al. 1988; Boisvieux-Ulrich et al. 1989). Recent work has provided further evidence that $\mathrm{BB}$ docking in MCCs indeed involves a ciliary vesicle. In Xenopus, BBs with tightly associated vesicles are seen during differentiation of control MCCs but not in Dvl morphants. Sec8, a component of a vesicle-trafficking complex called the exocyst, is present at BBs in control cells but not following Dvl depletion. This suggests that the PCP pathway controls the recruitment of Sec8-positive vesicles to the BBs to allow BB docking and ciliary membrane extension (Park et al. 2008). In agreement with this, the exocyst is required for primary ciliogenesis (Feng et al. 2012; Seixas et al. 2016). In mouse airway MCCs, ciliary vesicle docking further requires the $\mathrm{BB}$ component Chibby, which binds to CEP164 to promote the recruitment of Rabin8 and Rab8 (Burke et al. 2014). Primary cilium assembly also involves recruitment by CEP164 of tau tubulin kinase (TTBK2), which promotes the removal of the distal centriole component CP110 and the recruitment of the intraflagellar transport (IFT) machinery (Spektor et al. 2007; 
Goetz et al. 2012; Cajanek and Nigg 2014). $\mathrm{CP} 110$ is a distal centriole/BB that negatively regulates ciliogenesis by preventing growth of the axoneme (reviewed in Tsang and Dynlacht 2013). During differentiation of mouse and Xenopus MCCs, CP110 expression is repressed by the miR-34/449 microRNA. Inhibition of miR-34/449 induces a defect in ciliogenesis that can be rescued by codepleting CP110, indeed supporting that CP110 function is conserved in MCCs (Song et al. 2014).

Like for most ciliated cells, cilia assembly and maintenance in MCCs relies on the IFT machinery, a bidirectional transport system that moves ciliary components along axoneme microtubules. In vertebrates, mutations in IFT components that affect the assembly of primary cilia also usually affect the assembly of motile cilia (reviewed in Ishikawa and Marshall 2011; Sung and Leroux 2013; Lechtreck 2015). In addition, mutations that specifically affect ciliary motility are among the most frequent causes of primary ciliary dyskinesia (Lee 2011).

\section{CILIARY BEAT ORIENTATION}

\section{BB Organization}

In Xenopus MCCs, the subapical pool of actin is essential to $\mathrm{BB}$ proper spacing and orientation during MCC differentiation (Werner et al. 2011; Ioannou et al. 2013; Antoniades et al. 2014; Epting et al. 2015; Yasunaga et al. 2015). The subapical pool consists of actin bridges connecting the $\mathrm{BBs}$ along the axis of ciliary beating so that each $\mathrm{BB}$ is connected to the tip of the ciliary rootlet of the neighboring $\mathrm{BB}$ facing the direction of beating (Fig. 3) (Werner et al. 2011; Antoniades et al. 2014). Focal adhesion components are present at each end of these actin bridges, forming an apical ciliary adhesion in the vicinity of the basal foot and a subapical ciliary adhesion at the tip of the rootlet. A second set of actin bridges at a right angle with respect to the first set connects BBs laterally, likely also via the apical and subapical ciliary adhesions (Antoniades et al. 2014). In conditions that specifically disrupt the subapical actin pool but leave the apical network unaffected, such as low doses of the actin polymerization inhibitor cytochalasin D or partial inhibition of actin regulators, BBs dock but show defects in spacing (Werner et al. 2011; Ioannou et al. 2013; Antoniades et al. 2014; Epting et al. 2015; Yasunaga et al. 2015). These results support that subapical actin bridges are required for spacing BBs both along the axis of cilia orientation and perpendicular to this axis. MT depolymerization has no effect on BB spacing in Xenopus MCCs, but it does affect spacing in mouse tracheal cells, and so does inhibition of MT anchoring at the BBs, suggesting that some aspects of this process might be different between these species (Werner et al. 2011; Kunimoto et al. 2012; Vladar et al. 2012).

Disruption of the subapical actin network also impacts centriole rotational polarity (Werner et al. 2011; Ioannou et al. 2013; Yasunaga et al. 2015). Treating differentiating Xenopus MCCs with low doses of cytochalasin D results in a strong increase in $\mathrm{BB}$ circular standard deviation (CSD) across the cell surface, although $\mathrm{BB}$ orientation remains locally coordinated. In contrast, MT depolymerization disrupts the coordination of rotational polarity even between neighboring $\mathrm{BBs}$, supporting that actin and MTs control different aspects of BB rotational polarity (Werner et al. 2011). In mouse tracheal cells, tyrosinated MTs connect BBs to the cell junction in a polarized fashion, and transmission electron microscopy (TEM) analysis reveals the presence of MTs connecting the basal foot of peripheral BBs to the apical junctions (Vladar et al. 2012). Basal foot assembly requires a protein called ODF2/cenexin (Kunimoto et al. 2012), which is also a centrosome component essential for the assembly of mother centriole appendages (Ishikawa et al. 2005; Tateishi et al. 2013). Inactivation of Odf2 in mouse leads to centriole and ciliary beat disorientation in MCCs, in agreement with the MT drug experiments in the Xenopus skin (Werner et al. 2011; Kunimoto et al. 2012). The microtubule nucleator $\gamma$-tubulin localizes at the basal foot cap, which suggests that MTs are assembled from the basal foot (Hagiwara et al. 2000; Clare et al. 2014). Actin filaments emanating from the basal foot cap have also been observed in vari- 
ous species, which is in line with the observation that focal adhesion components localize in the vicinity of the basal foot in Xenopus (Fig. 3) (Reed et al. 1984; Sandoz et al. 1988; Chailley et al. 1989; Antoniades et al. 2014). In addition, connecting the basal foot to the cytoskeleton involves $\zeta$-tubulin in Xenopus MCCs. $\zeta$-tubulin localizes at the tip of the basal foot and is required for BB spacing and orientation. Interestingly, depletion of $\zeta$-tubulin does not affect binding of MTs to the basal feet, but it perturbs the assembly of the apical and subapical actin networks, which further suggests that basal feet connect BBs to the actin cytoskeleton (Turk et al. 2015). Mature MCCs in the quail oviduct contain a well-developed cytokeratin network that binds to desmosomes and to the striated rootlets, suggesting that intermediate filaments could also participate in BB organization in these cells (Lemullois et al. 1987).

\section{Polarization by the PCP Pathway}

The polarization of multiciliated epithelia involves not only the coordination of $\mathrm{BB}$ rotational polarity within cells but also between cells.
Both intracellular and tissue-level polarities are governed by the PCP pathway in vertebrate MCCs. Establishment of PCP at the tissue-level involves the asymmetric partitioning of PCP components at the cell cortex and intercellular communication to coordinate polarity between neighboring cells. In mouse ependymal MCCs, Vangl2 localizes transiently at the posterior side of the apical membrane (upstream of flow) during MCC differentiation (Guirao et al. 2010; Boutin et al. 2014). In tracheal cells, Vangl1/2 and $\mathrm{Pk} 2$ also localize upstream of flow at the posterior side, whereas Dvl1/3 and Fzd3/6 are at the opposite side (Vladar et al. 2012). In the Xenopus skin, a subset of PCP components displays an increasingly asymmetric distribution during MCC differentiation. Intriguingly, this distribution is reversed compared with that of mouse MCCs: Vangl1 and Pk2 localize downstream from flow, whereas Dvl1 and Fzd6 localize upstream of flow (Fig. 4) (Butler and Wallingford 2015).

In Drosophila, PCP components act noncell-autonomously to establish tissue-level polarity and this property is conserved in vertebrate MCCs. In Xenopus, expression of Vangl2

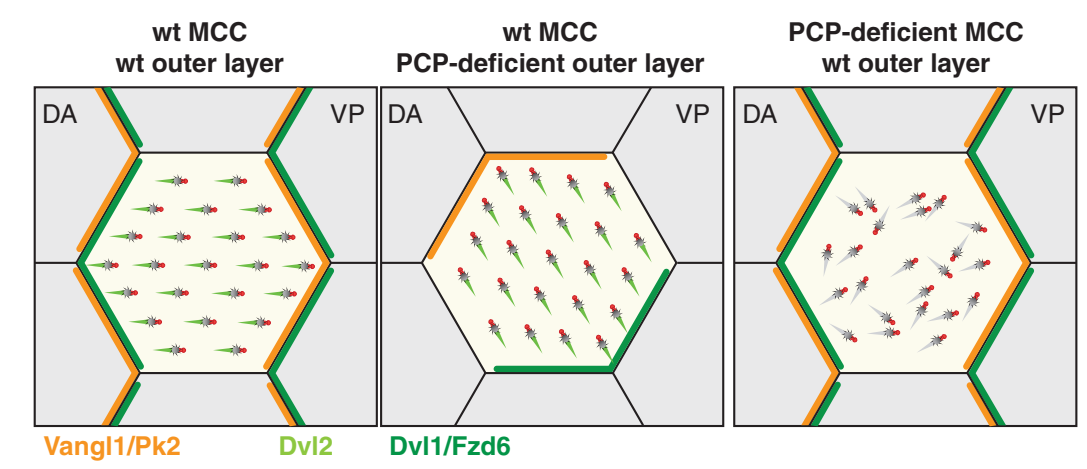

Figure 4. Multiciliated cell (MCC) polarization by the planar cell polarity (PCP) pathway in the Xenopus skin. Combined action of the PCP pathway and hydrodynamic forces align the BBs in a dorsoanterior (DA) to ventroposterior (VP) direction in wild-type (wt) Xenopus embryos. PCP components are asymmetrically distributed at the apical junctions, with a Dvl1/Fzd6 domain located upstream of flow and a Vangl1/Pk2 domain located downstream from flow (Butler and Wallingford 2015). When wt MCCs intercalate within a PCP-deficient outer epidermal layer in grafting experiments, intracellular basal body (BB) orientation is coordinated but improperly aligned with tissue polarity. When PCP-deficient MCCs intercalate within a wt outer layer, both intracellular and tissue-level polarity are lost (Mitchell et al. 2009). Note that in mouse ependymal and tracheal MCCs, the orientation of the Dvl/Fzd and Vangl/Pk domains with respect to the direction of ciliary beat is reversed (Vladar et al. 2012; Boutin et al. 2014). 
and Fzd3 in the outer epidermal layer is required for $\mathrm{BB}$ polarization in intercalating MCCs. When wild-type MCCs intercalate within a PCP-deficient outer layer, BB polarity is homogeneous within MCCs, but overall polarity with respect to the anterior-posterior (AP) axis is perturbed (Fig. 4) (Mitchell et al. 2009). In addition, the PCP pathway is required cell-autonomously to control BB docking and orientation in mouse and Xenopus (Park et al. 2008; Mitchell et al. 2009; Guirao et al. 2010; Vladar et al. 2012). Perturbation of Dvl function in differentiating Xenopus MCCs results in low coordination of $\mathrm{BB}$ orientation within cells even when they intercalate within a wild-type outer layer (Fig. 4) (Mitchell et al. 2009). In the mouse oviduct, Celsr1 depletion affects rotational polarity both within cells and between cells, although BBs remain locally coordinated with neighboring BBs (Shi et al. 2014). In ependymal MCCs, cilia are not present across the apical surface but clustered in a ciliary patch located toward the anterior end of the apical surface, a property called translational polarity (Mirzadeh et al. 2010). The PCP pathway controls both BB rotational and translational polarities by coordinating between adjacent cells the direction of $\mathrm{BB}$ orientation and that of $\mathrm{BB}$ cluster displacement-but not the displacement itself (Hirota et al. 2010; Mirzadeh et al. 2010; Tissir et al. 2010; Boutin et al. 2014; Ohata et al. 2014). Remarkably, translational polarity and rotational polarity involve partially distinct PCP components. Coordinating the direction of displacement of the $\mathrm{BB}$ cluster between cells requires Celsr1, whereas organization of BBs within a cluster requires Celsr2 and Celsr3 (Boutin et al. 2014). Translational polarity is first established in ependymal cell progenitors (radial glial cells [RGCs]) in which the primary cilium becomes off-centered in the anterior direction. The presence of a primary cilium in RGCs is essential for proper asymmetric localization of PCP components and localization of the BB cluster in ependymal cells (Mirzadeh et al. 2010). Remarkably, this function of the primary cilium depends on the mechanosensory proteins polycystic kidney disease (PKD) 1 and 2, which localize to the primary cilium in
RGCs. Primary cilia possibly sense a weak preexisting flow generated by the posterior secretion and anterior reabsorption of CSF and respond by polarizing in the direction of the flow (Ohata et al. 2015).

How does the PCP pathway control BB polarization in MCCs? The core PCP component Dvl2 localizes at the BBs to trigger RhoA activation and $\mathrm{BB}$ docking in the Xenopus skin (Park et al. 2008). Following BB docking and ciliogenesis, Dvl2 localizes at the ciliary rootlet in Xenopus and mouse MCCs (Park et al. 2008; Hirota et al. 2010; Vladar et al. 2012). Expression of the Dvl2 dominant-negative construct Xdd1 in the Xenopus skin disrupts BB orientation without affecting docking, supporting that these two aspects of Dvl2 function can be uncoupled (Park et al. 2008). Accumulation of Dvl2 at the base of cilia following inactivation of the anaphase-promoting complex, which targets Dvl2 for degradation, results in BB disorientation in the Xenopus skin, suggesting that $\mathrm{BB}$ polarization requires a tight control of Dvl2 levels at the BBs (Ganner et al. 2009). Besides Dvl2, diversin is present at the $\mathrm{BBs}$ in mouse airway and Xenopus skin MCCs (Yasunaga et al. 2011; Vladar et al. 2012), and Pk2 associates to BBs in mature Xenopus skin MCCs (Butler and Wallingford 2015). PCP effectors affecting the actin cytoskeleton such as inturned, DAAM1, and RhoA-GTP localize at the BBs, and following mild perturbations of these effectors BBs dock but fail to orient (Park et al. 2006, 2008; Yasunaga et al. 2015). Together, these data support that the PCP pathway locally controls actin assembly or remodeling to position the BBs. In addition, the establishment of tissue-level polarity requires coordinating $\mathrm{BB}$ orientation with the asymmetric PCP domains at the apical junctions. In mouse tracheal cells, MTs link the BBs to the apical junction corresponding to the Fzd3/6-Dvl1/3 domain (Vladar et al. 2012). In mature ependymal cells, MTs connects the BB cluster to the apical junction opposite to the Vangl2 domain, which corresponds to a presumptive Fzd3 domain (Boutin et al. 2014). PCP domains at the apical junctions most likely influence the polarity of the apical actin networks as well, particularly in Xenopus MCCs 
in which actin perturbation strongly impacts tissue-level polarity (Werner et al. 2011).

What acts upstream of the PCP pathway? A recent study found that mechanical strain imposed during gastrulation on Xenopus ectodermal cells, which gives rise to the larval epidermis, instructs planar polarity (Chien et al. 2015). During gastrulation, the ectoderm is strained along the AP axis by pulling forces generated by involution of the mesoderm. As a result, cells elongate and align apical MTs along the axis of the strain. Polarization of apical MTs then allows activation of PCP complexes specifically at apical junctions that are perpendicular to the axis of the strain. No clear asymmetric localization of PCP components is observed at this stage, but FRAP analysis shows that Fzd3GFP is stabilized on perpendicular junctions during gastrulation or under externally imposed strain (Chien et al. 2015). In differentiating MTECs as in other planar polarized tissues, apical MTs oriented in the axis of planar polarization are required for asymmetric localization of core PCP components (Shimada et al. 2006; Harumoto et al. 2010; Vladar et al. 2012). MTs are also required for asymmetric partitioning of PCP complexes during polarization of ependymal cells (Boutin et al. 2014). Thus, alignment of apical MTs is likely a conserved feature of PCP establishment in MCCs. Whether signaling cues only or a combination of signaling and mechanical cues acts upstream of the PCP pathway in other multiciliated epithelia remains to be determined.

\section{Hydrodynamic Forces}

Studies in Xenopus and mouse have shown that hydrodynamic forces play a major role in $\mathrm{BB}$ polarization by favoring the coordinated beating of neighboring cilia (Guirao and Joanny 2007; Mitchell et al. 2007; Guirao et al. 2010). In Xenopus MCCs, PCP signaling cues first induce a bias in the orientation of cilia beating (Park et al. 2008; Mitchell et al. 2009). This bias initiates a weak flow that establishes a positive-feedback loop in which cilia respond to the flow by refining their orientation until they are well aligned. Ciliary motility is essential for the re- finement of BB orientation (Mitchell et al. 2007). BBs fail to polarize in response to hydrodynamic forces following perturbation of either MTor actin networks, suggesting that the cytoskeleton is actively remodeled during this process (Werner et al. 2011). Unlike Xenopus, BBs dock in random orientation in mouse ependymal cells. In vitro differentiated ependymal cells submitted to a continuous shear flow align their cilia in the direction of the flow, and this response requires Vangl2. This suggests a model whereby ependymal cilia align in response to hydrodynamic forces initially generated by a weak preexisting CSF flow, in a PCP-dependent manner (Guirao et al. 2010). One possible model is that the PCP is required for remodeling the cytoskeleton to allow reorientation of the BBs. Ciliary motility is essential for this response as rotational polarity is altered in ependymal cells of the Hydin and Kintoun (Ktu) mutants, which assemble cilia with abnormal motility or fully immotile cilia, respectively (Lechtreck et al. 2008; Matsuo et al. 2013). Interestingly, ciliary motility is not required for the refinement of $\mathrm{BB}$ orientation in the trachea, because $\mathrm{Ktu}^{-/-}$mice display properly aligned $\mathrm{BBs}$ in this tissue (Matsuo et al. 2013). Like primary cilia, motile cilia in MCCs have sensory functions (Shah et al. 2009; Jain et al. 2012) and a proposed hypothesis is that MCC cilia could sense a bidirectional flow produced in the trachea through fetal breathing movements at the time when refinement occurs (Shah et al. 2009; Jain et al. 2012; Matsuo et al. 2013). Importantly, cilia realign in response to flow only during a developmental window during which MCCs polarize. Past this time, mature MCCs appear to lock their ciliary orientation (Boisvieux-Ulrich and Sandoz 1991; Mitchell et al. 2007; Guirao et al. 2010). The protein basal body orientation factor 1 (Bbof1), which localizes to the ciliary rootlet in Xenopus MCCs, is possibly involved in locking ciliary orientation, although the corresponding mechanism remains unclear (Chien et al. 2013).

\section{Regulation of Ciliary Beating}

Computational models support that the formation of metachronal waves in mature MCCs 
results from the local coordination of ciliary beat by hydrodynamic coupling (Guirao and Joanny 2007; Guirao et al. 2010; Elgeti and Gompper 2013). Coordination possibly involves a feedback mechanism that regulates the activity of axonemal dyneins in response to hydrodynamic cues (Rompolas et al. 2010). Formation of metachronal waves also requires the coordination of ciliary beat by the cytoskeleton. Disruption of the subapical actin bridges in already polarized Xenopus MCCs alters the ciliary beat coordination, suggesting that these bridges serve as a physical lever to facilitate propagation of the metachronal wave (Werner et al. 2011). In addition, hormonal or neurotransmitter control appears to affect ciliary beat in MCCs. In planarians, ablation of serotonergic neurons disrupts metachrony in the ventral epidermis without affecting the beating pattern of individual cilia (Currie and Pearson 2013). Serotonin-secreting cells are also present in the Xenopus skin, and serotonin regulates ciliary beat frequency in this tissue (Walentek et al. 2014). Ciliary beat frequency can also be regulated in response to external stimuli. In the mammalian airways, receptors to bitter compounds localize on motile cilia. In the presence of bitter compounds, intracellular calcium and ciliary beat frequency increase, thus providing a cell-autonomous mechanism to eliminate toxic compounds (Shah et al. 2009).

\section{CONCLUDING REMARKS}

Remarkable progress has been made during the past decade in our understanding of developmental and cellular mechanisms underlying MCC differentiation and function. In particular, the identification of the regulatory cascade controlling the specification and differentiation of MCCs in vertebrates opens important avenues in terms of both fundamental knowledge and biomedical applications. The ability to differentiate human MCCs in vitro from induced pluripotent stem cells constitutes a promising therapeutic approach for treating respiratory diseases known to affect the differentiation and function of MCCs, such as primary ciliary dyskinesia, cystic fibrosis, and severe asthma (Thomas et al. 2010; Firth et al. 2014; Hoegger et al. 2014).

There are many questions that remain to be addressed. Several of the identified regulators of MCC differentiation and BB assembly (MCIDAS, GEMC1, DEUP1) result from gene duplications that occurred in the vertebrate lineage. Did this regulatory network evolve to control the differentiation of mosaic multiciliated epithelia composed by distinct but highly related ciliated and mucus-secreting cells? How exactly do these regulators interact with each other to control MCC differentiation? Known deuterosome components include DEUP1, which by itself can form spherical structures resembling deuterosomes, and CCDC78 (Klos Dehring et al. 2013; Zhao et al. 2013). Are there other deuterosome components? How is deuterosome assembly regulated? In mouse MCCs, deuterosomes are assembled at the daughter centriole of the centrosome (Al Jord et al. 2014). Is this a conserved mechanism or are there differences between species? BB number in MCCs can vary up to 10 -fold depending on the tissue. How are these numbers controlled? The involvement of the PCP pathway and the cytoskeleton in coordinating $\mathrm{BB}$ migration, docking, and rotational polarity is now well established, but what are the precise mechanisms by which the PCP pathway controls the organization of actin and MTs? Hydrodynamic forces are required for achieving the proper polarization of ciliary beating. What are the respective impacts of ciliary motility and sensory functions in this process? With the current pace of discovery, we expect that many new findings will extend our understanding of MCC biology in a near future.

\section{ACKNOWLEDGMENTS}

The authors thank Andrea Aguilar, Camille Boutin, Bénédicte Durand, Laurent Kodjabachian, Brice Marcet, and Diego Revinski for useful comments on the manuscript. Our work is funded by Agence Nationale de la Recherche and La Ligue contre le Cancer. 
A. Meunier and J. Azimzadeh

\section{REFERENCES}

Adl SM, Simpson AG, Lane CE, Lukes J, Bass D, Bowser SS Brown MW, Burki F, Dunthorn M, Hampl V, et al. 2012. The revised classification of eukaryotes. J Eukaryot Microbiol 59: 429-493.

Al Jord A, Lemaitre AI, Delgehyr N, Faucourt, Spassky N, Meunier A. 2014. Centriole amplification by mother and daughter centrioles differs in multiciliated cells. Nature 516: 104-107.

Almuedo-Castillo M, Salo E, Adell T. 2011. Dishevelled is essential for neural connectivity and planar cell polarity in planarians. Proc Natl Acad Sci 108: 2813-2818.

Amirav I, Wallmeier J, Loges NT, Menchen T, Pennekamp P Mussaffi H, Abitbul R, Avital A, Bentur L, Dougherty GW, et al. 2016. Systematic analysis of CCNO variants in a defined population: Implications for clinical phenotype and differential diagnosis. Hum Mutat 37: 396-405.

Anderson RG. 1972. The three-dimensional structure of the basal body from the rhesus monkey oviduct. J Cell Biol 54: $246-265$.

Anderson RG, Brenner RM. 1971. The formation of basal bodies (centrioles) in the Rhesus monkey oviduct. J Cell Biol 50: 10-34.

Antoniades I, Stylianou P, Skourides PA. 2014. Making the connection: Ciliary adhesion complexes anchor basal bodies to the actin cytoskeleton. Dev Cell 28: 70-80.

Azimzadeh J. 2014. Exploring the evolutionary history of centrosomes. Philos Trans R Soc Lond B Biol Sci 369: 20130453.

Azimzadeh J, Wong ML, Downhour DM, Sanchez Alvarado A, Marshall WF. 2012. Centrosome loss in the evolution of planarians. Science 335: 461-463.

Balestrini A, Cosentino C, Errico A, Garner E, Costanzo V. 2010. GEMC1 is a TopBP1-interacting protein required for chromosomal DNA replication. Nat Cell Biol 12: 484-491.

Basquin C, Orfila AM, Azimzadeh J. 2015. The planarian Schmidtea mediterranea as a model for studying motile cilia and multiciliated cells. Methods Cell Biol 127: 243262.

Bayly R, Axelrod JD. 2011. Pointing in the right direction: New developments in the field of planar cell polarity. Nat Rev Genet 12: 385-391.

Boisvieux-Ulrich E, Sandoz D. 1991. Determination of ciliary polarity precedes differentiation in the epithelial cells of quail oviduct. Biol Cell 72: 3-14.

Boisvieux-Ulrich E, Laine MC, Sandoz D. 1989. In vitro effects of taxol on ciliogenesis in quail oviduct. J Cell Sci 92: 9-20.

Boisvieux-Ulrich E, Laine MC, Sandoz D. 1990. Cytochala$\sin \mathrm{D}$ inhibits basal body migration and ciliary elongation in quail oviduct epithelium. Cell Tissue Res 259: 443454.

Boon M, Wallmeier J, Ma L, Loges NT, Jaspers M, Olbrich H, Dougherty GW, Raidt J, Werner C, Amirav I, et al. 2014. MCIDAS mutations result in a mucociliary clearance disorder with reduced generation of multiple motile cilia. Nat Commun 5: 4418.

Boury-Esnault N, Efremova S, Bézac C, Vacelet J. 1999. Reproduction of a hexactinellid sponge: First description of gastrulation by cellular delamination in the Porifera. Invertebr Reprod Dev 35: 187-201.

Boutin C, Labedan P, Dimidschstein J, Richard F, Cremer H, Andre P, Yang Y, Montcouquiol M, Goffinet AM, Tissir F. 2014. A dual role for planar cell polarity genes in ciliated cells. Proc Natl Acad Sci 111: E3129-E3138.

Brightman MW, Palay SL. 1963. The fine structure of ependyma in the brain of the rat. J Cell Biol 19: 415-439.

Brody SL, Yan XH, Wuerffel MK, Song SK, Shapiro SD. 2000. Ciliogenesis and left-right axis defects in forkhead factor HFH-4-null mice. Am J Respir Cell Mol Biol 23: $45-51$.

Brown NJ, Marjanovic M, Luders J, Stracker TH, Costanzo V. 2013. Cep63 and cep152 cooperate to ensure centriole duplication. PLoS ONE 8: e69986.

Burke MC, Li FQ, Cyge B, Arashiro T, Brechbuhl HM, Chen X, Siller SS, Weiss MA, O'Connell CB, Love D, et al. 2014. Chibby promotes ciliary vesicle formation and basal body docking during airway cell differentiation. J Cell Biol 207: 123-137.

Butler MT, Wallingford JB. 2015. Control of vertebrate core planar cell polarity protein localization and dynamics by Prickle 2. Development 142: 3429-3439.

Cajanek L, Nigg EA. 2014. Cep164 triggers ciliogenesis by recruiting Tau tubulin kinase 2 to the mother centriole. Proc Natl Acad Sci 111: E2841-E2850.

Chailley B, Nicolas G, Laine MC. 1989. Organization of actin microfilaments in the apical border of oviduct ciliated cells. Biol Cell 67: 81-90.

Chen J, Knowles HJ, Hebert JL, Hackett BP. 1998. Mutation of the mouse hepatocyte nuclear factor/forkhead homologue 4 gene results in an absence of cilia and random left-right asymmetry. J Clin Invest 102: 1077-1082.

Chevalier B, Adamiok A, Mercey O, Revinski DR, Zaragosi LE, Pasini A, Kodjabachian L, Barbry P, Marcet B. 2015. miR-34/449 control apical actin network formation during multiciliogenesis through small GTPase pathways. Nat Commun 6: 8386.

Chien YH, Werner ME, Stubbs J, Joens MS, Li J, Chien S, Fitzpatrick JA, Mitchell BJ, Kintner C. 2013. Bbof1 is required to maintain cilia orientation. Development 140: $3468-3477$.

Chien YH, Keller R, Kintner C, Shook DR. 2015. Mechanical strain determines the axis of planar polarity in ciliated epithelia. Curr Biol 25: 2774-2784.

Choksi SP, Lauter G, Swoboda P, Roy S. 2014. Switching on cilia: Transcriptional networks regulating ciliogenesis. Development 141: 1427-1441.

Chung MI, Peyrot SM, LeBoeuf S, Park TJ, McGary KL, Marcotte EM, Wallingford JB. 2012. RFX2 is broadly required for ciliogenesis during vertebrate development. Dev Biol 363: 155-165.

Chung MI, Kwon T, Tu F, Brooks ER, Gupta R, Meyer M, Baker JC, Marcotte EM, Wallingford JB. 2014. Coordinated genomic control of ciliogenesis and cell movement by RFX2. eLife 3: e01439.

Cibois M, Luxardi G, Chevalier B, Thome V, Mercey O, Zaragosi, Barbry P, Pasini A, Marcet B, Kodjabachian L. 2015. BMP signalling controls the construction of vertebrate mucociliary epithelia. Development 142: $2352-$ 2363. 
Clare DK, Magescas J, Piolot T, Dumoux M, Vesque C, Pichard E, Dang T, Duvauchelle B, Poirier F, Delacour D. 2014. Basal foot MTOC organizes pillar MTs required for coordination of beating cilia. Nat Commun 5: 4888 .

Currie KW, Pearson BJ. 2013. Transcription factors $\operatorname{lh} x 1 / 5-1$ and pitx are required for the maintenance and regeneration of serotonergic neurons in planarians. Development 140: $3577-3588$

Cuschieri A, Bannister LH. 1975. The development of the olfactory mucosa in the mouse: Electron microscopy. $J$ Anat 119: 471-498.

Danielian PS, Bender Kim CF, Caron AM, Vasile E, Bronson RT, Lees JA. 2007. E2f4 is required for normal development of the airway epithelium. Dev Biol 305: 564-576.

Danielian PS, Hess RA, Lees JA. 2016. E2f4 and E2f5 are essential for the development of the male reproductive system. Cell Cycle 15: 250-260.

Deblandre GA, Wettstein DA, Koyano-Nakagawa N, Kintner C. 1999. A two-step mechanism generates the spacing pattern of the ciliated cells in the skin of Xenopus embryos. Development 126: $4715-4728$.

Devenport D. 2014. The cell biology of planar cell polarity. $J$ Cell Biol 207: 171-179.

Didon L, Zwick RK, Chao IW, Walters MS, Wang R, Hackett NR, Crystal RG. 2013. RFX3 modulation of FOXJ1 regulation of cilia genes in the human airway epithelium. Respir Res 14: 70.

Dirksen ER. 1971. Centriole morphogenesis in developing ciliated epithelium of the mouse oviduct. J Cell Biol 51: 286-302.

Elgeti J, Gompper G. 2013. Emergence of metachronal waves in cilia arrays. Proc Natl Acad Sci 110: 4470-4475.

El Zein L, Ait-Lounis A, Morle L, Thomas J, Chhin B, Spassky N, Reith W, Durand B. 2009. RFX3 governs growth and beating efficiency of motile cilia in mouse and controls the expression of genes involved in human ciliopathies. J Cell Sci 122: 3180-3189.

Epting D, Slanchev K, Boehlke C, Hoff S, Loges NT, Yasunaga T, Indorf L, Nestel S, Lienkamp SS, Omran H, et al. 2015. The Racl regulator ELMO controls basal body migration and docking in multiciliated cells through interaction with Ezrin. Development 142: 174-184.

Feng S, Knodler A, Ren J, Zhang J, Zhang X, Hong Y, Huang S, Peranen J, Guo W. 2012. A Rab8 guanine nucleotide exchange factor-effector interaction network regulates primary ciliogenesis. J Biol Chem 287: 15602-15609.

Firat-Karalar EN, Stearns T. 2014. The centriole duplication cycle. Philos Trans R Soc Lond B Biol Sci 369: 20130460.

Firth AL, Dargitz CT, Qualls SJ, Menon T, Wright R, Singer O, Gage FH, Khanna A, Verma IM. 2014. Generation of multiciliated cells in functional airway epithelia from human induced pluripotent stem cells. Proc Natl Acad Sci 111: E1723-E1730.

Funk MC, Bera AN, Menchen T, Kuales G, Thriene K, Lienkamp SS, Dengjel J, Omran H, Frank M, Arnold SJ. 2015. Cyclin $\mathrm{O}(\mathrm{Ccno})$ functions during deuterosome-mediated centriole amplification of multiciliated cells. EMBO J 34: 1078-1089.

Ganner A, Lienkamp S, Schafer T, Romaker D, Wegierski T, Park TJ, Spreitzer S, Simons M, Gloy J, Kim E, et al. 2009.
Regulation of ciliary polarity by the APC/C. Proc Natl Acad Sci 106: 17799-17804.

Gegg M, Bottcher A, Burtscher I, Hasenoeder S, Van Campenhout C, Aichler M, Walch A, Grant SG, Lickert H. 2014. Flattop regulates basal body docking and positioning in mono- and multiciliated cells. eLife 3: 03842.

Gibbons IR. 1961. The relationship between the fine structure and direction of beat in gill cilia of a lamellibranch mollusc. J Biophys Biochem Cytol 11: 179-205.

Giribet G, Ribera C. 1998. The position of arthropods in the animal kingdom: A search for a reliable outgroup for internal arthropod phylogeny. Mol Phylogenet Evol 9: $481-488$.

Goetz SC, Anderson KV. 2010. The primary cilium: A signalling centre during vertebrate development. Nat Rev Genet 11: 331-344.

Goetz SC, Liem KF Jr, Anderson KV. 2012. The spinocerebellar ataxia-associated gene Tau tubulin kinase 2 controls the initiation of ciliogenesis. Cell 151: 847-858.

Gomi K, Arbelaez V, Crystal RG, Walters MS. 2015. Activation of NOTCH1 or NOTCH3 signaling skews human airway basal cell differentiation toward a secretory pathway. PLoS ONE 10: e0116507.

Gomperts BN, Gong-Cooper X, Hackett BP. 2004. Foxj1 regulates basal body anchoring to the cytoskeleton of ciliated pulmonary epithelial cells. J Cell Sci 117: 13291337.

Goodrich LV, Strutt D. 2011. Principles of planar polarity in animal development. Development 138: 1877-1892.

Guirao B, Joanny JF. 2007. Spontaneous creation of macroscopic flow and metachronal waves in an array of cilia. Biophys J 92: 1900-1917.

Guirao B, Meunier A, Mortaud S, Aguilar A, Corsi JM, Strehl L, Hirota Y, Desoeuvre A, Boutin C, Han YG, et al. 2010. Coupling between hydrodynamic forces and planar cell polarity orients mammalian motile cilia. Nat Cell Biol 12: 341-350.

Guseh JS, Bores SA, Stanger BZ, Zhou Q, Anderson WJ, Melton DA, Rajagopal J. 2009. Notch signaling promotes airway mucous metaplasia and inhibits alveolar development. Development 136: 1751-1759.

Hagiwara H. 1995. Electron microscopic studies of ciliogenesis and ciliary abnormalities in human oviduct epithelium. Ital J Anat Embryol 100: 451-459.

Hagiwara H, Kano A, Aoki T, Ohwada N, Takata K. 2000. Localization of $\gamma$-tubulin to the basal foot associated with the basal body extending a cilium. Histochem J 32: 669671.

Hansen A, Zeiske E. 1993. Development of the olfactory organ in the zebrafish, Brachydanio rerio. J Comp Neurol 333: $289-300$

Harumoto T, Ito M, Shimada Y, Kobayashi TJ, Ueda HR, Lu B, Uemura T. 2010. Atypical cadherins Dachsous and Fat control dynamics of noncentrosomal microtubules in planar cell polarity. Dev Cell 19: 389-401.

Hepler PK. 1976. The blepharoplast of Marsilea: Its de novo formation and spindle association. J Cell Sci 21:361-390.

Hirota Y, Meunier A, Huang S, Shimozawa T, Yamada O, Kida YS, Inoue M, Ito T, Kato H, Sakaguchi M, et al. 2010. Planar polarity of multiciliated ependymal cells involves 
the anterior migration of basal bodies regulated by nonmuscle myosin II. Development 137: 3037-3046.

Hodges ME, Scheumann N, Wickstead B, Langdale JA, Gull K. 2010. Reconstructing the evolutionary history of the centriole from protein components. J Cell Sci 123: 14071413.

Hoegger MJ, Fischer AJ, McMenimen JD, Ostedgaard LS, Tucker AJ, Awadalla MA, Moninger TO, Michalski AS, Hoffman EA, Zabner J, et al. 2014. Impaired mucus detachment disrupts mucociliary transport in a piglet model of cystic fibrosis. Science 345: 818-822.

Hoh RA, Stowe TR, Turk E, Stearns T. 2012. Transcriptional program of ciliated epithelial cells reveals new cilium and centrosome components and links to human disease. PLoS ONE 7: e52166.

Ioannou A, Santama N, Skourides PA. 2013. Xenopus laevis nucleotide binding protein 1 (xNubp1) is important for convergent extension movements and controls ciliogenesis via regulation of the actin cytoskeleton. Dev Biol 380: 243-258.

Ishikawa H, Marshall WF. 2011. Ciliogenesis: Building the cell's antenna. Nat Rev Mol Cell Biol 12: 222-234.

Ishikawa H, Kubo A, Tsukita S. 2005. Odf2-deficient mother centrioles lack distal/subdistal appendages and the ability to generate primary cilia. Nat Cell Biol 7: 517-524.

Jain R, Javidan-Nejad C, Alexander-Brett J, Horani A, Cabellon MC, Walter MJ, Brody SL. 2012. Sensory functions of motile cilia and implication for bronchiectasis. Front Biosci (Schol Ed) 4: 1088-1098.

Kalnins VI, Porter KR. 1969. Centriole replication during ciliogenesis in the chick tracheal epithelium. Z Zellforsch Mikrosk Anat 100: 1-30.

Katz SM, Morgan JJ. 1984. Cilia in the human kidney. Ultrastruct Pathol 6: 285-294.

Kessler M, Hoffmann K, Brinkmann V, Thieck O, Jackisch S, Toelle B, Berger H, Mollenkopf HJ, Mangler M, Sehouli J, et al. 2015. The Notch and Wnt pathways regulate stemness and differentiation in human fallopian tube organoids. Nat Commun 6: 8989.

Klos Dehring DA, Vladar EK, Werner ME, Mitchell JW, Hwang P, Mitchell BJ. 2013. Deuterosome-mediated centriole biogenesis. Dev Cell 27: 103-112.

Klotz C, Bordes N, Laine MC, Sandoz D, Bornens M. 1986. Myosin at the apical pole of ciliated epithelial cells as revealed by a monoclonal antibody. J Cell Biol 103: 613-619.

Kramer-Zucker AG, Olale F, Haycraft CJ, Yoder BK, Schier AF, Drummond IA. 2005. Cilia-driven fluid flow in the zebrafish pronephros, brain and Kupffer's vesicle is required for normal organogenesis. Development 132: 1907-1921.

Kroll KL. 2007. Geminin in embryonic development: Coordinating transcription and the cell cycle during differentiation. Front Biosci 12: 1395-1409.

Kunimoto K, Yamazaki Y, Nishida T, Shinohara K, Ishikawa H, Hasegawa T, Okanoue T, Hamada H, Noda T, Tamura A, et al. 2012. Coordinated ciliary beating requires Odf2mediated polarization of basal bodies via basal feet. Cell 148: $189-200$.

Kyrousi C, Arbi M, Pilz GA, Pefani DE, Lalioti ME, Ninkovic J, Gotz M, Lygerou Z, Taraviras S. 2015. Mcidas and
GemC1 are key regulators for the generation of multiciliated ependymal cells in the adult neurogenic niche. Development 142: 3661-3674.

Lafkas D, Shelton A, Chiu C, de Leon Boenig G, Chen Y, Stawicki SS, Siltanen C, Reichelt M, Zhou M, Wu X, et al. 2015. Therapeutic antibodies reveal Notch control of transdifferentiation in the adult lung. Nature 528: 127131.

Lechtreck KF. 2015. IFT-cargo interactions and protein transport in cilia. Trends Biochem Sci 40: 765-778.

Lechtreck KF, Delmotte P, Robinson ML, Sanderson MJ, Witman GB. 2008. Mutations in Hydin impair ciliary motility in mice. J Cell Biol 180: 633-643.

Lee L. 2011. Mechanisms of mammalian ciliary motility: Insights from primary ciliary dyskinesia genetics. Gene 473: 57-66.

Lee L. 2013. Riding the wave of ependymal cilia: Genetic susceptibility to hydrocephalus in primary ciliary dyskinesia. J Neurosci Res 91: 1117-1132.

Lemullois M, Gounon P, Sandoz D. 1987. Relationships between cytokeratin filaments and centriolar derivatives during ciliogenesis in the quail oviduct. Biol Cell 61:3949.

Lemullois M, Boisvieux-Ulrich E, Laine MC, Chailley B, Sandoz D. 1988. Development and functions of the cytoskeleton during ciliogenesis in metazoa. Biol Cell 63: 195-208.

Liu Y, Pathak N, Kramer-Zucker A, Drummond IA. 2007. Notch signaling controls the differentiation of transporting epithelia and multiciliated cells in the zebrafish pronephros. Development 134: 1111-1122.

Lu Q, Insinna C, Ott C, Stauffer J, Pintado PA, Rahajeng J, Baxa U, Walia V, Cuenca A, Hwang YS, et al. 2015. Early steps in primary cilium assembly require EHD1/EHD3dependent ciliary vesicle formation. Nat Cell Biol 17: $228-240$.

Lukinavicius G, Lavogina D, Orpinell M, Umezawa K, Reymond L, Garin N, Gonczy P, Johnsson K. 2013. Selective chemical crosslinking reveals a Cep57-Cep63-Cep152 centrosomal complex. Curr Biol 23: 265-270.

Ma M, Jiang YJ. 2007. Jagged2a-notch signaling mediates cell fate choice in the zebrafish pronephric duct. PLoS Genet 3: e18.

Ma JY, Ou-Yang YC, Luo YB, Wang ZB, Hou Y, Han ZM, Liu Z, Schatten H, Sun QY. 2013. Cyclin O regulates germinal vesicle breakdown in mouse oocytes. Biol Reprod 88: 110.

Ma L, Quigley I, Omran H, Kintner C. 2014. Multicilin drives centriole biogenesis via E2f proteins. Genes Dev 28: 1461-1471.

Marcet B, Chevalier B, Luxardi G, Coraux C, Zaragosi LE, Cibois M, Robbe-Sermesant K, Jolly T, Cardinaud B, Moreilhon C, et al. 2011. Control of vertebrate multiciliogenesis by miR-449 through direct repression of the Delta/Notch pathway. Nat Cell Biol 13: 693-699.

Matsuo M, Shimada A, Koshida S, Saga Y, Takeda H. 2013. The establishment of rotational polarity in the airway and ependymal cilia: Analysis with a novel cilium motility mutant mouse. Am J Physiol Lung Cell Mol Physiol 304: L736-L745. 
Menard D. 1995. Morphological studies of the developing human esophageal epithelium. Microsc Res Tech 31:215225.

Mikrjukov K, Mylnikov A. 1998. The fine structure of a carnivorous multiflagellar protist, Multicilia marina Cienkowski, 1881 (flagellata incertae sedis). Eur J Protistol 34: 391-401.

Mirzadeh Z, Han YG, Soriano-Navarro M, Garcia-Verdugo JM, Alvarez-Buylla A. 2010. Cilia organize ependymal planar polarity. J Neurosci 30: 2600-2610.

Mitchell B, Jacobs R, Li J, Chien S, Kintner C. 2007. A positive feedback mechanism governs the polarity and motion of motile cilia. Nature 447: 97-101.

Mitchell B, Stubbs JL, Huisman F, Taborek P, Yu C, Kintner C. 2009. The PCP pathway instructs the planar orientation of ciliated cells in the Xenopus larval skin. Curr Biol 19: 924-929.

Miyatake K, Kusakabe M, Takahashi C, Nishida E. 2015 ERK7 regulates ciliogenesis by phosphorylating the actin regulator CapZIP in cooperation with Dishevelled. Nat Commun 6: 6666.

Mizukami I, Gall J. 1966. Centriole replication. II: Sperm formation in the fern, Marsilea, and the cycad, Zamia. J Cell Biol 29: 97-111.

Mori M, Mahoney JE, Stupnikov MR, Paez-Cortez JR, Szymaniak AD, Varelas X, Herrick DB, Schwob J, Zhang H, Cardoso WV. 2015. Notch3-Jagged signaling controls the pool of undifferentiated airway progenitors. Development 142: $258-267$.

Morimoto M, Liu Z, Cheng HT, Winters N, Bader D, Kopan R. 2010. Canonical Notch signaling in the developing lung is required for determination of arterial smooth muscle cells and selection of Clara versus ciliated cell fate. J Cell Sci 123: 213-224.

Ohata S, Nakatani J, Herranz-Perez V, Cheng J, Belinson H, Inubushi T, Snider WD, Garcia-Verdugo JM, WynshawBoris A, Alvarez-Buylla A. 2014. Loss of Dishevelleds disrupts planar polarity in ependymal motile cilia and results in hydrocephalus. Neuron 83: 558-571.

Ohata S, Herranz-Perez V, Nakatani J, Boletta A, GarciaVerdugo JM, Alvarez-Buylla A. 2015. Mechanosensory genes $P k d 1$ and $P k d 2$ contribute to the planar polarization of brain ventricular epithelium. J Neurosci 35: 11153-11168.

Pan J, You Y, Huang T, Brody SL. 2007. RhoA-mediated apical actin enrichment is required for ciliogenesis and promoted by Foxj1. J Cell Sci 120: 1868-1876.

Pardo-Saganta A, Law BM, Tata PR, Villoria J, Saez B, Mou H, Zhao R, Rajagopal J. 2015a. Injury induces direct lineage segregation of functionally distinct airway basal stem/progenitor cell subpopulations. Cell Stem Cell 16: 184-197.

Pardo-Saganta A, Tata PR, Law BM, Saez B, Chow R, Prabhu M, Gridley T, Rajagopal J. 2015b. Parent stem cells can serve as niches for their daughter cells. Nature 523: 597601.

Park TJ, Haigo SL, Wallingford JB. 2006. Ciliogenesis defects in embryos lacking inturned or fuzzy function are associated with failure of planar cell polarity and Hedgehog signaling. Nat Genet 38: 303-311.
Park TJ, Mitchell BJ, Abitua PB, Kintner C, Wallingford JB. 2008. Dishevelled controls apical docking and planar polarization of basal bodies in ciliated epithelial cells. Nat Genet 40: 871-879.

Pefani DE, Dimaki M, Spella M, Karantzelis N, Mitsiki E, Kyrousi C, Symeonidou IE, Perrakis A, Taraviras S, Lygerou Z. 2011. Idas, a novel phylogenetically conserved geminin-related protein, binds to geminin and is required for cell cycle progression. J Biol Chem 286: 23234-23246.

Popatia R, Haver K, Casey A. 2014. Primary ciliary dyskinesia: An update on new diagnostic modalities and review of the literature. Pediatr Allergy Immunol Pulmonol 27: 51-59.

Ramsay RG, Gonda TJ. 2008. MYB function in normal and cancer cells. Nat Rev Cancer 8: 523-534.

Rawlins EL, Okubo T, Xue Y, Brass DM, Auten RL, Hasegawa H, Wang F, Hogan BL. 2009. The role of Scgbla1 ${ }^{+}$Clara cells in the long-term maintenance and repair of lung airway, but not alveolar, epithelium. Cell Stem Cell 4: 525-534.

Reed W, Avolio J, Satir P. 1984. The cytoskeleton of the apical border of the lateral cells of freshwater mussel gill: Structural integration of microtubule and actin filament-based organelles. J Cell Sci 68: 1-33.

Reiter JF, Blacque OE, Leroux MR. 2012. The base of the cilium: Roles for transition fibres and the transition zone in ciliary formation, maintenance and compartmentalization. EMBO Rep 13: 608-618.

Reverdin N, Gabbiani G, Kapanci Y. 1975. Actin in tracheobronchial ciliated epithelial cells. Experientia 31: 1348 1350.

Rieger RM. 1981. Morphology of the Turbellaria at the ultrastructural level. Hydrobiologia 84: 213-229.

Rink JC, Vu HT, Sanchez Alvarado A. 2011. The maintenance and regeneration of the planarian excretory system are regulated by EGFR signaling. Development 138: 3769-3780.

Rock JR, Hogan BL. 2011. Epithelial progenitor cells in lung development, maintenance, repair, and disease. Annu Rev Cell Dev Biol 27: 493-512.

Rohatgi R, Snell WJ. 2010. The ciliary membrane. Curr Opin Cell Biol 22: 541-546.

Roig MB, Roset R, Ortet L, Balsiger NA, Anfosso A, Cabellos L, Garrido M, Alameda F, Brady HJ, Gil-Gomez G. 2009. Identification of a novel cyclin required for the intrinsic apoptosis pathway in lymphoid cells. Cell Death Differ 16: 230-243.

Rompolas P, Patel-King RS, King SM. 2010. An outer arm dynein conformational switch is required for metachronal synchrony of motile cilia in planaria. Mol Biol Cell 21: 3669-3679.

Rompolas P, Azimzadeh J, Marshall WF, King SM. 2013. Analysis of ciliary assembly and function in planaria. Method Enzymol 525: 245-264.

Sadasivam S, DeCaprio JA. 2013. The DREAM complex: Master coordinator of cell cycle-dependent gene expression. Nat Rev Cancer 13: 585-595.

Sandoz D, Boisvieux-Ulrich E. 1976. Ciliogenesis in the mucous cells of the quail oviduct. I: Ultrastructural study in the laying quail. J Cell Biol 71: 449-459. 
Sandoz D, Boisvieux-Ulrich E, Laugier C, Brard E. 1976. Ciliogenesis in the mucous cells of the quail oviduct. II: Hormonal control. J Cell Biol 71: 460-471.

Sandoz D, Chailley B, Boisvieux-Ulrich E, Lemullois M, Laine MC, Bautista-Harris G. 1988. Organization and functions of cytoskeleton in metazoan ciliated cells. Biol Cell 63: 183-193.

Schmidt KN, Kuhns S, Neuner A, Hub B, Zentgraf H, Pereira G. 2012. Cep164 mediates vesicular docking to the mother centriole during early steps of ciliogenesis. J Cell Biol 199: $1083-1101$.

Seixas C, Choi SY, Polgar N, Umberger NL, East MP, Zuo X, Moreiras H, Ghossoub R, Benmerah A, Kahn RA, et al. 2016. Arl13b and the exocyst interact synergistically in ciliogenesis. Mol Biol Cell 27: 308-320.

Shah AS, Ben-Shahar Y, Moninger TP, Kline JN, Welsh MJ. 2009. Motile cilia of human airway epithelia are chemosensory. Science 325: 1131-1134.

Shi D, Komatsu K, Hirao M, Toyooka Y, Koyama H, Tissir F, Goffinet M, Uemura T, Fujimori T. 2014. Celsr1 is required for the generation of polarity at multiple levels of the mouse oviduct. Development 141: 4558-4568.

Shimada Y, Yonemura S, Ohkura H, Strutt D, Uemura T. 2006. Polarized transport of Frizzled along the planar microtubule arrays in Drosophila wing epithelium. Dev Cell 10: 209-222.

Sir JH, Barr AR, Nicholas AK, Carvalho OP, Khurshid M, Sossick A, Reichelt S, D'Santos C, Woods CG, Gergely F. 2011. A primary microcephaly protein complex forms a ring around parental centrioles. Nat Genet 43: $1147-$ 1153.

Song R, Walentek P, Sponer N, Klimke A, Lee JS, Dixon G, Harland R, Wan Y, Lishko P, Lize M, et al. 2014. miR-34/ 449 miRNAs are required for motile ciliogenesis by repressing cp110. Nature 510: 115-120.

Sorokin S. 1962. Centrioles and the formation of rudimentary cilia by fibroblasts and smooth muscle cells. J Cell Biol 15: 363-377.

Sorokin SP. 1968. Reconstructions of centriole formation and ciliogenesis in mammalian lungs. J Cell Sci 3: 207230.

Spektor A, Tsang WY, Khoo D, Dynlacht BD. 2007. Cep97 and CP110 suppress a cilia assembly program. Cell 130: 678-690.

Steinman RM. 1968. An electron microscopic study of ciliogenesis in developing epidermis and trachea in the embryo of Xenopus laevis. Am J Anat 122: 19-55.

Stubbs JL, Vladar EK, Axelrod JD, Kintner C. 2012. Multicilin promotes centriole assembly and ciliogenesis during multiciliate cell differentiation. Nat Cell Biol 14: 140147.

Sung CH, Leroux MR. 2013. The roles of evolutionarily conserved functional modules in cilia-related trafficking. Nat Cell Biol 15: 1387-1397.

Tamm S, Tamm SL. 1988. Development of macrociliary cells in Beroe. I: Actin bundles and centriole migration. J Cell Sci 89: 67-80.

Tamm SL, Sonneborn TM, Dippell RV. 1975. The role of cortical orientation in the control of the direction of ciliary beat in paramecium. J Cell Biol 64: 98-112.
Tan FE, Vladar EK, Ma L, Fuentealba LC, Hoh R, Espinoza FH, Axelrod JD, Alvarez-Buylla A, Stearns T, Kintner C, et al. 2013. Myb promotes centriole amplification and later steps of the multiciliogenesis program. Development 140: 4277-4286.

Tateishi K, Yamazaki Y, Nishida T, Watanabe S, Kunimoto K, Ishikawa H, Tsukita S. 2013. Two appendages homologous between basal bodies and centrioles are formed using distinct Odf2 domains. J Cell Biol 203: 417-425.

Thi-Kim Vu H, Rink JC, McKinney SA, McClain M, Lakshmanaperumal N, Alexander R, Sanchez Alvarado A. 2015. Stem cells and fluid flow drive cyst formation in an invertebrate excretory organ. eLife 4: e07405.

Thomas B, Rutman A, Hirst RA, Haldar P, Wardlaw AJ, Bankart J, Brightling CE, O'Callaghan C. 2010. Ciliary dysfunction and ultrastructural abnormalities are features of severe asthma. J Allergy Clin Immunol 126: 722-729.e2.

Tissir F, Qu Y, Montcouquiol M, Zhou L, Komatsu K, Shi D, Fujimori T, Labeau J, Tyteca D, Courtoy P, et al. 2010. Lack of cadherins Celsr2 and Celsr3 impairs ependymal ciliogenesis, leading to fatal hydrocephalus. Nat Neurosci 13: 700-707.

Tsang WY, Dynlacht BD. 2013. CP110 and its network of partners coordinately regulate cilia assembly. Cilia 2: 9.

Tsao PN, Vasconcelos M, Izvolsky KI, Qian J, Lu J, Cardoso WV. 2009. Notch signaling controls the balance of ciliated and secretory cell fates in developing airways. Development 136: 2297-2307.

Turk E, Wills AA, Kwon T, Sedzinski J, Wallingford JB, Stearns T. 2015. Zeta-tubulin is a member of a conserved tubulin module and is a component of the centriolar basal foot in multiciliated cells. Curr Biol 25: 2177-2183.

Tyler S. 1981. Development of cilia in embryos of the turbellarian Macrostomum. Hydrobiologia 84: 231-239.

Vize PD, Carroll TJ, Wallingford JB. 2003. Induction, development, and physiology of the pronephric tubules. In The kidney: From normal development to congenital disease (ed. Vize PD, Woolf AS, Bard JBL), pp. 19-50. Academic, San Diego.

Vladar EK, Bayly RD, Sangoram AM, Scott MP, Axelrod JD. 2012. Microtubules enable the planar cell polarity of airway cilia. Curr Biol 22: 2203-2212.

Walentek P, Bogusch S, Thumberger T, Vick P, Dubaissi E, Beyer T, Blum M, Schweickert A. 2014. A novel serotoninsecreting cell type regulates ciliary motility in the mucociliary epidermis of Xenopus tadpoles. Development 141: $1526-1533$.

Walentek P, Hagenlocher C, Beyer T, Muller C, Feistel K, Schweickert A, Harland RM, Blum M. 2015. ATP4 and ciliation in the neuroectoderm and endoderm of Xenopus embryos and tadpoles. Data Brief 4: 22-31.

Wallmeier J, Al-Mutairi DA, Chen CT, Loges NT, Pennekamp P, Menchen T, Ma L, Shamseldin HE, Olbrich H, Dougherty GW, et al. 2014. Mutations in CCNO result in congenital mucociliary clearance disorder with reduced generation of multiple motile cilia. Nat Genet 46: 646651.

Wang L, Fu C, Fan H, Du T, Dong M, Chen Y, Jin Y, Zhou Y, Deng M, Gu A, et al. 2013. miR-34b regulates multiciliogenesis during organ formation in zebrafish. Development 140: $2755-2764$. 
Watson JK, Rulands S, Wilkinson AC, Wuidart A, Ousset M, Van Keymeulen A, Gottgens B, Blanpain C, Simons BD, Rawlins EL. 2015. Clonal dynamics reveal two distinct populations of basal cells in slow-turnover airway epithelium. Cell Rep 12: 90-101.

Wei Q, Ling K, Hu J. 2015. The essential roles of transition fibers in the context of cilia. Curr Opin Cell Biol 35: 98 105.

Werner ME, Mitchell BJ. 2012. Understanding ciliated epithelia: The power of Xenopus. Genesis 50: 176-185.

Werner ME, Hwang P, Huisman F, Taborek P, Yu CC, Mitchell BJ. 2011. Actin and microtubules drive differential aspects of planar cell polarity in multiciliated cells. $J$ Cell Biol 195: 19-26.

Yasunaga T, Itoh K, Sokol SY. 2011. Regulation of basal body and ciliary functions by diversin. Mech Dev 128: $376-$ 386.

Yasunaga T, Hoff S, Schell C, Helmstadter M, Kretz O, Kuechlin S, Yakulov TA, Engel C, Muller B, Bensch R, et al. 2015. The polarity protein inturned links NPHP4 to
Daam1 to control the subapical actin network in multiciliated cells. J Cell Biol 211: 963-973.

Ying G, Avasthi P, Irwin M, Gerstner CD, Frederick JM, Lucero MT, Baehr W. 2014. Centrin 2 is required for mouse olfactory ciliary trafficking and development of ependymal cilia planar polarity. J Neurosci 34: 63776388.

Yu X, Ng CP, Habacher H, Roy S. 2008. Foxj1 transcription factors are master regulators of the motile ciliogenic program. Nat Genet 40: 1445-1453.

Zhao H, Zhu L, Zhu Y, Cao J, Li S, Huang Q, Xu T, Huang X, Yan X, Zhu X. 2013. The Cep63 paralogue Deup1 enables massive de novo centriole biogenesis for vertebrate multiciliogenesis. Nat Cell Biol 15: 1434-1444.

Zhou F, Narasimhan V, Shboul M, Chong YL, Reversade B, Roy S. 2015. Gmnc is a master regulator of the multiciliated cell differentiation program. Curr Biol 25: 3267 3273.

Zielinski B, Hara TJ. 1988. Morphological and physiological development of olfactory receptor cells in rainbow trout (Salmo gairdneri) embryos. J Comp Neurol 271:300-311. 


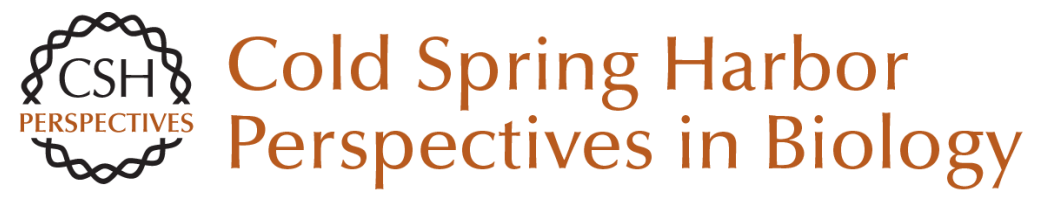

\section{Multiciliated Cells in Animals}

Alice Meunier and Juliette Azimzadeh

Cold Spring Harb Perspect Biol 2016; doi: 10.1101/cshperspect.a028233 originally published online August 31, 2016

\section{Subject Collection Cilia}

Ciliary Mechanisms of Cyst Formation in Polycystic Kidney Disease

Ming Ma, Anna-Rachel Gallagher and Stefan Somlo

Photoreceptor Cilia and Retinal Ciliopathies Kinga M. Bujakowska, Qin Liu and Eric A. Pierce

G-Protein-Coupled Receptor Signaling in Cilia Kirk Mykytyn and Candice Askwith

Evolution of Cilia David R. Mitchell

Transition Zone Migration: A Mechanism for Cytoplasmic Ciliogenesis and Postaxonemal Centriole Elongation

Tomer Avidor-Reiss, Andrew Ha and Marcus L. Basiri

Cilia and Obesity

Christian Vaisse, Jeremy F. Reiter and Nicolas F. Berbari

Posttranslational Modifications of Tubulin and Cilia

Dorota Wloga, Ewa Joachimiak, Panagiota Louka, et al.
Cilia in Left-Right Symmetry Breaking Kyosuke Shinohara and Hiroshi Hamada

Discovery, Diagnosis, and Etiology of Craniofacial Ciliopathies Elizabeth N. Schock and Samantha A. Brugmann

Axoneme Structure from Motile Cilia Takashi Ishikawa

Cilia and Ciliopathies in Congenital Heart Disease Nikolai T. Klena, Brian C. Gibbs and Cecilia W. Lo

Sperm Sensory Signaling Dagmar Wachten, Jan F. Jikeli and U. Benjamin Kaupp

\section{Primary Cilia and Coordination of Receptor} Tyrosine Kinase (RTK) and Transforming Growth Factor $\beta$ (TGF- $\beta$ ) Signaling Søren T. Christensen, Stine K. Morthorst, Johanne B. Mogensen, et al.

Primary Cilia and Mammalian Hedgehog Signaling Fiona Bangs and Kathryn V. Anderson

For additional articles in this collection, see http://cshperspectives.cshlp.org/cgi/collection/

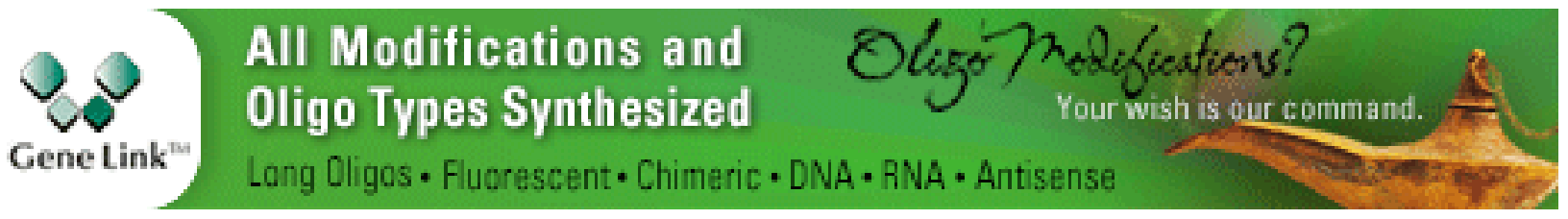


Radial Spokes--A Snapshot of the Motility Regulation, Assembly, and Evolution of Cilia and Flagella

Xiaoyan Zhu, Yi Liu and Pinfen Yang
Cilia and Mucociliary Clearance

Ximena M. Bustamante-Marin and Lawrence E. Ostrowski

For additional articles in this collection, see http://cshperspectives.cshlp.org/cgi/collection/

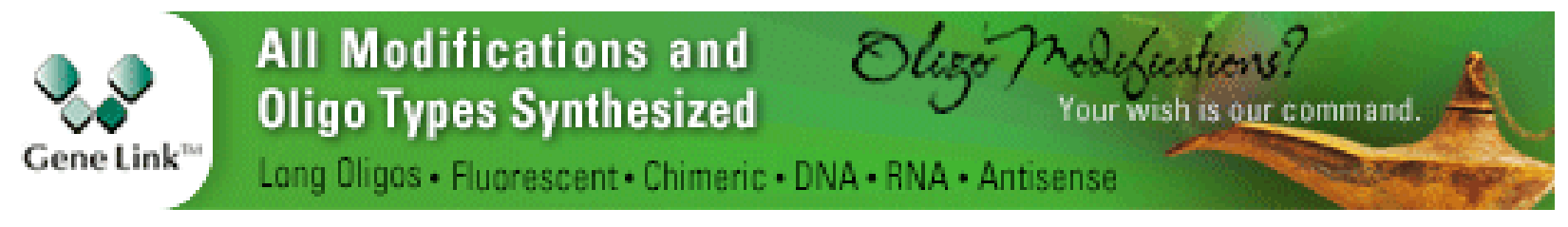

Copyright @ 2016 Cold Spring Harbor Laboratory Press; all rights reserved 